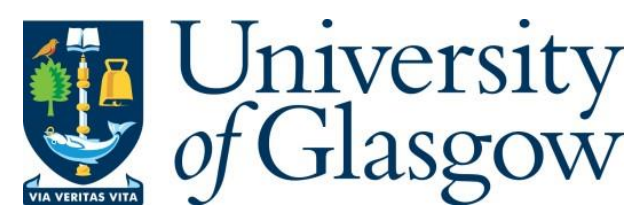

Dung, N.T., Hooper, T.J.N. and Unluer, C. (2020) Enhancing the performance of MgOactivated slag-fly ash mixes by accelerated carbonation. Journal of CO2 Utilization, 42, 101356.

There may be differences between this version and the published version. You are advised to consult the publisher's version if you wish to cite from it.

$\underline{\text { http://eprints.gla.ac.uk/229181/ }}$

Deposited on: 17 February 2021

Enlighten - Research publications by members of the University of Glasgow http://eprints.gla.ac.uk 


\section{Enhancing the performance of MgO-activated slag-fly ash mixes by accelerated} carbonation

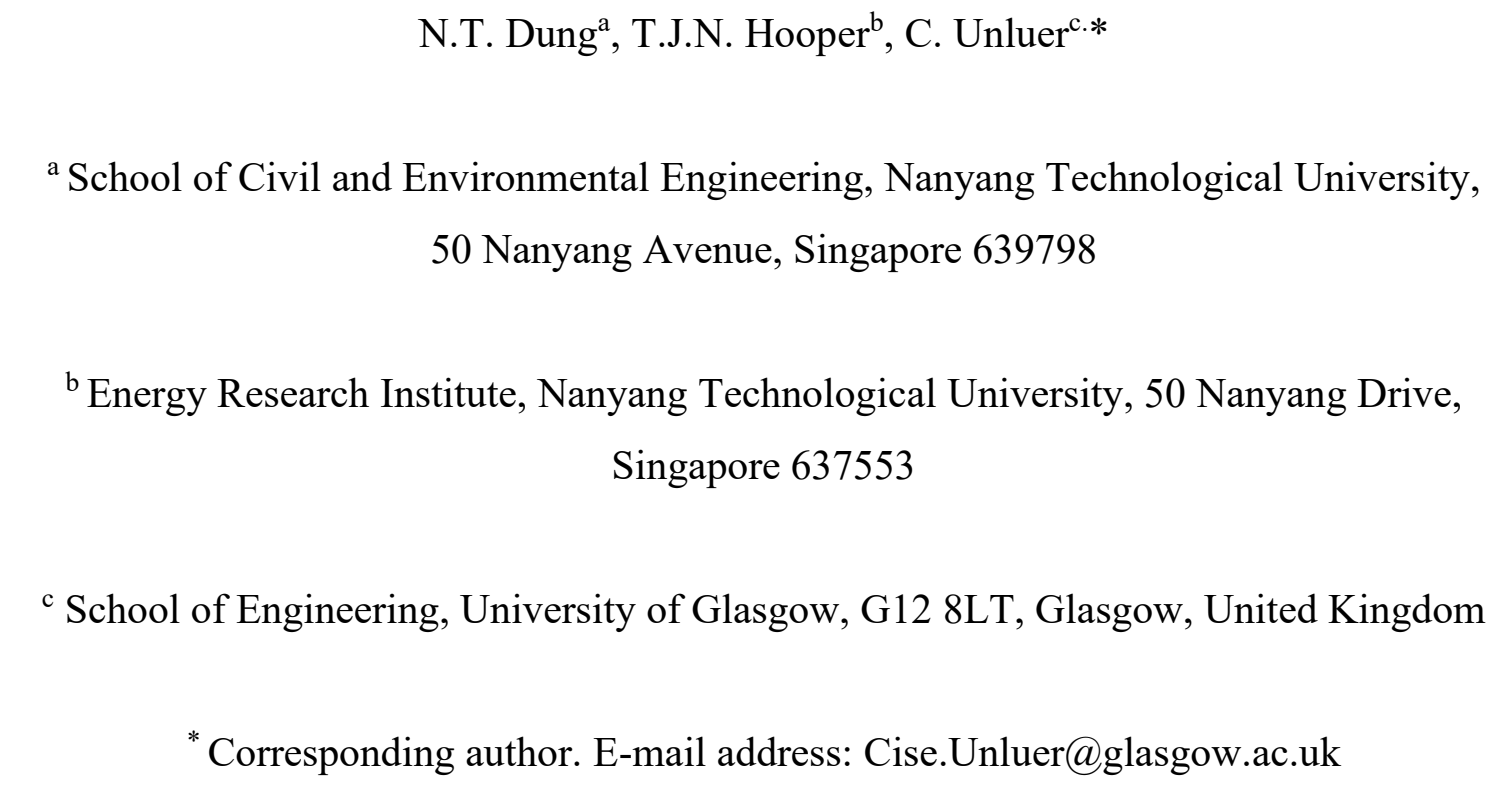

\section{Abstract}

This study focused on the development of reactive $\mathrm{MgO}(\mathrm{RM})$ activated-GGBS binders containing fly ash (FA). Performance of these binders was aimed to be improved by enhancing the hydration of RM and dissolution of GGBS and FA via high temperature pre-curing (HTPC); and conversion of unreacted phases into carbonates via carbonation. Spherical FA particles mitigated inter-particle surface frictions and improved flow. Although the use of HTPC accelerated the hydration of $\mathrm{MgO}$, rapid precipitation of brucite hindered the dissolution of GGBS and FA and formation of associated hydration products. Transformation of RM into hydrated magnesium carbonates (HMCs) under carbonation led to significant improvements in sample performance via the pore filling effect and binding strength provided by HMCs, despite the degradation of ettringite and C-(A)-S-H during carbonation. Inclusion of $12 \% \mathrm{FA}$ resulted in comparable strengths to the control sample, highlighting the feasibility of incorporating FA within RM activated-GGBS samples without compromising performance.

33 Keywords: $\mathrm{MgO}$; granulated blast furnace slag; fly ash; curing; microstructure 
Portland cement (PC) production is energy intensive, requires the use of natural resources and leads to the emissions of $\sim 8 \%$ of total global anthropogenic $\mathrm{CO}_{2}$ emissions [1]. One of the alternative binders being developed to alleviate these effects involves the use of alkali-activated ground granulated blast-furnace slag (GGBS), which could present a sustainable alternative to $\mathrm{PC}$ due to its lower energy and resource consumption as well as lower $\mathrm{CO}_{2}$ emissions associated with the reuse of by-products.

The alkali activation process involves the dissolution of the oxide in slag (e.g. Si-O-Si, Al-O$\mathrm{Al}, \mathrm{Al}-\mathrm{O}-\mathrm{Si}$ and $\mathrm{Ca}-\mathrm{O})$ by an alkaline activator, followed by the formation of a $\mathrm{Si}-\mathrm{Al}$ layer, crystal hydrotalcite and calcium aluminate silicate hydrate C-(A)-S-H phases [2-6]. Despite presenting a satisfactory performance, the practical application of strong alkalis is restricted by their flash setting, high drying shrinkage, difficulty of handling the caustic alkali and potential of alkali-aggregated reaction [7-9]. Another factor that needs to be considered is the high amounts of $\mathrm{CO}_{2}$ emissions and energy demand linked with the production of activators.

Previous studies [10-12] demonstrated the use of reactive $\mathrm{MgO}$ (RM) as an activator to produce sustainable alkali-activated GGBS (AAS)-based cementitious binders that could be more economical and without significant caustic and drying shrinkage issues. Within the RM activated-GGBS system, C-(A)-S-H and hydrotalcite are the primary hydration products contributing to strength gain $[11,13,14]$, in addition to magnesium silicate hydrate (M-S-H) and ettringite [15]. The $\mathrm{CaO}$ content and reactivity of $\mathrm{RM}$ activator are the main factors controlling the alkalinity of the system, which determines the dissolution of GGBS and subsequent strength development [16]. Previous applications of RM activated-GGBS formulations involve soil stabilization, resulting in higher compressive strengths than corresponding PC-stabilized soil samples [17-19]. RM activated-GGBS can also be used for the stabilization of marine soft clay, resulting in a higher resistance to sodium sulfate attack than PC stabilized clay [20].

Despite these advantages, the use of RM as an activator for GGBS has not been largely practiced mainly because of its low hydration degree [21] and subsequently low strength gain. Accordingly, RM-GGBS pastes with a water/binder ratio of 0.5 was reported to reveal 28-day compressive strengths of $<20 \mathrm{MPa}[11,14,16]$. This low strength was associated with a 
considerable amount of unhydrated $\mathrm{MgO}$ observed in these mixes even after 28 days of hydration $[11,14]$. One potential way to improve the hydration of RM involves the elevation of the curing temperature to enhance the diffusion of water and increase the rate of $\mathrm{MgO}$ dissolution [17, 21-23], thereby accelerating the activation of GGBS, for which RM is used as an activator.

Fly ash (FA), which is also a by-product obtained from coal combustion in electric power plants, could eliminate the friction between GGBS grains and improve the workability of these systems in line with the spherical nature of its particles [24]. In spite of this advantage, FA has not been used in RM-activated systems due to its higher activation energy demand than GGBS [25] and the low alkalinity of hydrated $\mathrm{MgO}$. Accordingly, the low reactivity of FA was reported to delay the setting time and reduce the early compressive strength of PC-FA and alkali-activated FA mixes [26]. However, if unused, the direct disposal of FA to landfills causes environmental problems including the leaching of metals and pollution of air and water resources. These issues could be resolved by the inclusion of FA within cementitious mixes, in which it can play a role in the reaction process and associated strength development via the improvement of its dissolution [17, 26, 27]. Therefore, in addition to preventing any contamination of natural resources due to its disposal, the use of FA in these mixes could both contribute to fresh properties by providing improved workability [28, 29] and potentially performance.

Keeping these factors in mind, this study focuses on the development of sustainable binders involving the use of RM activated-GGBS that includes FA, the combination of which has not been widely reported in the literature until now. Within these binders, the hydration of RM and the dissolution of GGBS and FA were enhanced via the adjustment of the curing temperature $[21,30]$. Further improvements in the performance of the developed RM activated-GGBS-FA samples were achieved via the conversion of the unhydrated $\mathrm{MgO}$ into hydrated magnesium carbonates (HMCs) such as rosette-like hydromagnesite $\left(4 \mathrm{MgCO}_{3} \cdot \mathrm{Mg}(\mathrm{OH})_{2} \cdot 4 \mathrm{H}_{2} \mathrm{O}\right)$, needlelike nesquehonite $\left(\mathrm{MgCO}_{3} \cdot 3 \mathrm{H}_{2} \mathrm{O}\right)$, and acicular artinite $\left(\mathrm{MgCO}_{3} \cdot \mathrm{Mg}(\mathrm{OH})_{2} \cdot 3 \mathrm{H}_{2} \mathrm{O}\right)[31,32]$. This was enabled by subjecting the samples to elevated concentrations of $\mathrm{CO}_{2}$ during curing $[33,34]$. The utilization of high concentrations of $\mathrm{CO}_{2}$ in the carbonation process not only led to a reduction in porosity and provided a binding network facilitated by the formation of HMCs, thereby improving sample performance [21, 30, 31, 35, 36], but also shed light on the feasibility of reducing $\mathrm{CO}_{2}$ emissions asscociated with cement production. 
To achieve these, the mechanical and microstructural properties of RM activated-GGBS-FA formulations with varying compositions were evaluated under different curing conditions. The prepared concrete samples were cured under two different temperatures $\left(30^{\circ} \mathrm{C}\right.$ and $\left.50^{\circ} \mathrm{C}\right)$ for 28 days, prior to being carbonated under $10 \% \mathrm{CO}_{2}$ for 70 days. The effect of temperature on the reaction kinetics was assessed via the heat evolution during hydration, measured by isothermal calorimetry. The evaluation of compressive strength at different curing durations, was followed by a detailed microstructural assessment involving x-ray diffraction (XRD), ${ }^{27} \mathrm{Al}$ and ${ }^{29} \mathrm{Si}$ solid-state nuclear magnetic resonance (NMR), thermogravimetry-differential thermogravimetry (TG-DTG) and scanning electron microscopy (SEM) analyses.

\section{Materials and Methodology}

\subsection{Materials}

118 In this study, RM (obtained from Richard Baker Harrison, UK), GGBS and FA (both obtained 119 from Engro Corporation, Singapore) were used to form the main binder component. The 120 chemical and physical properties of RM and FA (provided by the suppliers) and those of GGBS 121 (obtained from x-ray fluorescence analysis) are shown in Table 1. XRD patterns of RM, GGBS and FA (Fig. 1) indicated that the main peak for RM was recorded at $43.8^{\circ} 2 \theta$. The crystalline phases of GGBS were at $\sim 25^{\circ} 2 \theta$ (gehlenite $\left(\mathrm{Ca}_{2} \mathrm{Al}(\mathrm{Al} \mathrm{SiO})\right.$, PDF\# 01-073-6601) and $\sim 30^{\circ}$ $2 \theta$ (sodium aluminum silicate $\left(\mathrm{Na}_{2} \mathrm{Al}_{2} \mathrm{Si}_{7.2} \mathrm{O}_{18.4}\right)$, PDF\# 00-056-0486), in addition to its amorphous phase at $\sim 25-35^{\circ} 2 \theta$. FA included the crystalline phases of quartz $\left(\mathrm{SiO}_{2}, \mathrm{PDF} \# 01-\right.$ 070-7344) and mullite ( $\mathrm{Al}_{4.52} \mathrm{Si}_{1.48} \mathrm{O}_{9.74}, \mathrm{PDF} \#$ 00-056-0486), in addition to a broad amorphous

127 hump at $\sim 15-25^{\circ} 2 \theta$. Fig. 2 shows the morphology of each component, where the angular and 128 irregular grains of RM and GGBS, in contrast to the spherical particles of FA, were observed. 129 The particle size distribution of RM, GGBS and FA is shown in Fig. 3, revealing the relatively comparable profiles of GGBS and FA.

132 For the preparation of concrete samples, saturated surface dry aggregates with a particle size of 4.7-9.5 $\mathrm{mm}$ were used. This study omitted the use of sand in the designed mix compositions 
to avoid the presence of quartz or clay, with the goal of increasing the accuracy of the phase quantifications.

\subsection{Methodology}

The detailed mix designs of concrete samples prepared in this study are provided in Table 2 .

141 The control sample (0FA) involved the use of $20 \% \mathrm{RM}$ as an alkali activator with $80 \%$ GGBS (i.e. by mass), based on preliminary studies and previous findings [11]. FA partially replaced GGBS at a content of $15 \%$ and $30 \%$, corresponding to $12 \%$ and $24 \%$ of the total binder (i.e. by mass), in samples 12FA and 24FA, respectively. The water/binder (w/b) ratio was kept constant at 0.5 for all mixes, in which the binder was composed of RM, GGBS and FA.

A homogenous mixture was obtained after 6 minutes of mixing. The concrete samples were cast into cubic molds $(50 \times 50 \times 50 \mathrm{~mm})$, consolidated and finished by a trowel. All samples were demoulded after 24 hours. One set of samples was cured under ambient conditions $\left(30 \pm 2^{\circ} \mathrm{C}\right.$, $80 \pm 4 \% \mathrm{RH}$ ) for 28 days. Another set of samples was cured under high temperature pre-curing (HTPC) conditions $\left(50^{\circ} \mathrm{C}, 80 \% \mathrm{RH}\right)$ for 7 days to accelerate the hydration process, followed by curing under ambient conditions $\left(30 \pm 2^{\circ} \mathrm{C}, 80 \pm 4 \% \mathrm{RH}\right)$ for 21 days (i.e. the total curing duration was 28 days). Samples cured under ambient conditions were labeled as 0FA, 12FA and 24FA; while those subjected to HTPC were labeled as T.0FA, T.12FA and T.24FA. Once the 28 days of curing were completed, both set of samples were subjected to accelerated carbonation under an elevated $\mathrm{CO}_{2}$ concentration to increase the rate of the carbonation reaction. In line with the findings of previous studies [33, 37], $10 \% \mathrm{CO}_{2}$ was determined as an ideal concentration for the microstructural and mechanical development of the prepared samples, which were cured under $10 \% \mathrm{CO}_{2}, 30 \pm 1^{\circ} \mathrm{C}$ and $80 \pm 2 \% \mathrm{RH}$. Following the results presented in earlier studies [30], the carbonation duration was extended up to 70 days (i.e. the total curing duration was 98 days) to demonstrate the effect of carbonation in the long term. In practice, the $\mathrm{CO}_{2}$ that could be used in the curing of the proposed samples could be captured from coal power plants and any other industrial plants such as cement plants that release $\mathrm{CO}_{2}$ throughout their operation. The $\mathrm{CO}_{2}$ captured from these sources could be directed for the curing of these concrete samples to reduce the overall global anthropogenic $\mathrm{CO}_{2}$ emissions associated with cement production and use. 
In addition to concrete samples, corresponding paste compositions were prepared to investigate the fresh properties and the influence of curing conditions on the hydration kinetics of RM activated GGBS-FA samples. The paste mixes were prepared by mixing water and binder with the same mixture proportions provided in Table 2.

\subsection{1 pH test}

Pastes with a w/b ratio of 0.5 were prepared for the $\mathrm{pH}$ test. After mixing and vacuum filtration, the $\mathrm{pH}$ value of the filtered solution was measured by a Mettler Toledo $\mathrm{pH}$ meter. The reported results were the average values of three measurements.

\subsubsection{Flow and setting time}

The flow test was carried out on pastes with a w/b ratio of 0.5 by measuring the increase in the average base diameter of each sample according to ASTM C 1437-15 [38]. The setting time of the same pastes was assessed by using a Vicat apparatus according to ASTM C191 -13 [39]. The reported results were the average of four measurements.

\subsubsection{Isothermal calorimetry}

The heat release within each sample was measured at $30^{\circ} \mathrm{C}$ and $50^{\circ} \mathrm{C}$ by an I-Cal $8000 \mathrm{High}$ Precision calorimeter. Solid powders (RM, GGBS and FA) and water were pre-heated in the calorimeter to the measurement temperatures $\left(30^{\circ} \mathrm{C}\right.$ and $\left.50^{\circ} \mathrm{C}\right)$. When thermal equilibrium was reached, water was mixed with the solid powders, and the paste samples were immediately placed into individual calorimeter channels to record the hydration heat for 48 hours.

\subsubsection{Compressive strength}

The prepared samples were tested for their compressive strength at 1, 3, 7, 14 and 28 days of curing under ambient and HTPC conditions. The performance of samples subjected to 
accelerated carbonation was assessed at 14, 28, 56 and 70 days of carbonation. All tests were performed at a loading rate of $55 \mathrm{kN} / \mathrm{min}$ and each of the reported strength values were the average of three measurements.

\subsubsection{XRD, ${ }^{27} \mathrm{Al}$ and ${ }^{29} \mathrm{Si}$ NMR, TG-DTG and SEM analyses}

Samples extracted from all of the 6 faces of the concrete cubes were stored in isopropanol and dried in vacuum, followed by grinding down to pass through a $75 \mu \mathrm{m}$ sieve before $\mathrm{XRD},{ }^{27} \mathrm{Al}$ and ${ }^{29} \mathrm{Si}$ NMR and TG-DTG analyses. Each XRD, NMR and TG-DTG analysis required around $2 \mathrm{~g}, 100 \mathrm{mg}$ and 20-30 mg of powder samples, respectively.

XRD analysis was performed on a Philips PW 1800 spectrometer applying $\mathrm{Cu}_{\alpha}$ radiation (40 $\mathrm{kV}, 30 \mathrm{~mA}$ ). The samples were scanned between from 5 to $80^{\circ} 2 \theta$ with a scanning rate of $0.04^{\circ}$ $2 \theta$ /step. Fluorite $\left(\mathrm{CaF}_{2}\right)$, used as an internal standard, was added to powder samples by $5 \mathrm{wt} . \%$ to enable the quantification of key phases within each formulation.

Solid-state NMR data was acquired on a 14.1 T Bruker Avance III HD spectrometer with a Bruker $4 \mathrm{~mm}$ MAS probe [5]. The ${ }^{27} \mathrm{Al}$ NMR $\left(v_{0}=156.35 \mathrm{MHz}\right)$ one-pulse experiment used a $14 \mathrm{kHz}$ MAS frequency, a $1 \mu \mathrm{s}(\pi / 6)$ pulse length and a $1 \mathrm{~s}$ relaxation delay. The ${ }^{29} \mathrm{Si} \mathrm{NMR}\left(v_{0}\right.$ $=119.23 \mathrm{MHz}$ ) one-pulse experiment used a $12 \mathrm{kHz}$ MAS frequency, a $5.3 \mu \mathrm{s}(\pi / 2)$ pulse length and a $30 \mathrm{~s}$ recycle delay. The ${ }^{27} \mathrm{Al}$ and ${ }^{29} \mathrm{Si} \mathrm{NMR}$ data were referenced with respect to

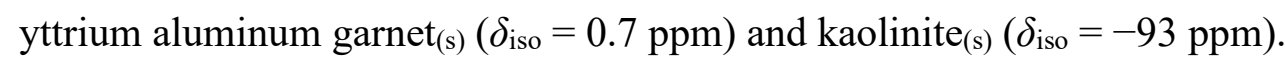

TG-DTG was performed between $30^{\circ} \mathrm{C}$ and $900^{\circ} \mathrm{C}$ under $\mathrm{N}_{2}$, at a heating rate of $10^{\circ} \mathrm{C} / \mathrm{min}$ in a Perkin Elmer TGA 4000 equipment. To quantify the amount of hydrate and carbonate phases in each sample, DTG curves were deconvoluted according to the Gaussian method using Origin 2017 software, which led to different deconvoluted components corresponding to the decomposition of each phase. The area of each deconvoluted component represented the decomposition of each phase. The vacuum dried samples were coated with gold before SEM analysis to investigate the morphologies of the hydration and carbonation products by using a Zeiss Evo 50 microscope.

$$
\text { Zeiss Evo } 50 \text { microscope. }
$$




\section{$3 \quad$ Results and Discussion}

\subsection{Fresh properties}

Table 3 presents the fresh properties of RM activated-GGBS-FA pastes. Along with RM, the presence of impurities such as $\mathrm{CaO}$ in $\mathrm{RM}$ increased the $\mathrm{pH}$ of the liquid phase within the samples, revealing comparable $\mathrm{pH}$ values at around $\sim 12$ for all three samples. In terms of the flow values, the inclusion of FA had a direct influence on the workability and resulted in an improvement in the flow, which was directly proportional with the FA content. This improvement was associated with the mitigation of the inter-particle surface frictions of the angular RM and GGBS grains by the spherical FA grains. Furthermore, the use of FA reduced the potential for agglomeration, thereby releasing the water trapped within flocs [24, 28, 29] and resulting in an increase in the flow of pastes from 163\% (in sample 0FA) to $190-201 \%$ (in samples 12FA and 24FA). Alternatively, the use of FA resulted in longer initial setting times, which went up from $7.75 \mathrm{~h}$ (in sample 0FA) to 10.25-10.75 h (in samples 12FA and 24FA). This effect was less pronounced in the final setting time, which ranged between 16.5 and 18.5 $\mathrm{h}$ for all samples.

\subsection{Isothermal calorimetry}

Fig. 4 shows isothermal calorimetry results of all pastes that were hydrated under $30^{\circ} \mathrm{C}$ and $50^{\circ} \mathrm{C}$ for 48 hours. Samples hydrated under $30^{\circ} \mathrm{C}$ (0FA, 12FA and 24FA) revealed one induction period in between two exothermal peaks (Fig. 4 (a)). The initial sharp peak that occurred instantly after mixing corresponded to the dissolution of RM, followed by an increase in the alkalinity of the liquid phase within the sample, enabling the dissolution of GGBS and FA. Accordingly, the second broad acceleration peak, occurring at around 6-30 hours was attributed to the polymerization of the silicate and aluminate, and the formation of reaction products. The induction period between these exothermal peaks was associated with an increase in the dissolved phases to reach a critical concentration, followed by the formation of the reaction products. Samples 12FA and 24FA presented lower acceleration peaks than sample OFA, which was associated with the presence of FA, which did not contribute to the overall heat evolution as much as GGBS. 
270 On the other hand, the heat flow demonstrated by samples hydrated at $50^{\circ} \mathrm{C}$ (i.e. T.0FA, 271 T.12FA and T.24FA) revaled a single intensive peak, indicating the rapid precipitation of 272 hydrate phases after the dissolution of precursors. The significantly earlier appearance and 273 higher intensity of the exothermal peak of the samples subjected to HTPC (T.0FA, T.12FA and 274 T.24FA) in comparison to those cured under ambient conditions (0FA, 12FA and 24FA) 275 indicated the acceleration of the reaction kinetics and rapid precipitation of hydrate phases under $50^{\circ} \mathrm{C}$. However, most of this acceleration was completed after $\sim 16$ hours, followed by a minor heat flow; whereas the acceleration-deceleration period lasted from $\sim 6$ to $\sim 30$ hours in samples cured under ambient conditions.

The cumulative heat results (Fig. 4 (b)) revealed the effect of FA content on the total heat release, which was more pronounced for those cured under $30^{\circ} \mathrm{C}$. Accordingly, a reduction in the cumulative heat was observed with an increase in the FA content, which was in line with the trends observed in the intensity of the acceleration peak shown in Fig. 4 (a). While there was a notable increase in the rate of heat evolved during the first $\sim 16$ hours of hydration under $50^{\circ} \mathrm{C}$ in comparison to $30^{\circ} \mathrm{C}$, these samples gradually produced a comparable amount of cumulative heat with the rest of the samples. Therefore, the use of HTPC was only effective in the acceleration of reaction kinetics and precipitation of hydrate phases at early stages, whereas those cured under $30^{\circ} \mathrm{C}$ gradually produced a similar, if not higher, amount of heat in the longer periods. Accordingly, the control sample (0FA) revealed the highest amount of cumulative heat at the end of 48 hours, followed by those cured under $50^{\circ} \mathrm{C}$, showing that the binder composition had a more prominent effect on reaction mechanisms than temperature in the long term.

\subsection{Compressive strength}

Fig. 5 demonstrates the strength development of samples cured under ambient and HTPC conditions. In agreement with the isothermal calorimetry results, the higher rate of dissolution and precipitation of hydrate phases at early stages enabled samples subjected to HTPC (T.0FA, T.12FA and T.24FA) to gain higher compressive strengths than those cured under ambient conditions (0FA, 12FA and 24FA) during the first 7 days. However, as curing proceeded, HTPC samples presented a slower strength gain, resulting in comparable performances to those cured under ambient conditions. In both curing conditions, the inclusion of $12 \% \mathrm{FA}$ produced 
similar strength results as the control sample, whereas an increase in the FA content to $24 \%$ in samples 24FA and T.24FA reduced the compressive strength by $\sim 20 \%$ when compared with samples 0FA and T.0FA. These results highlighted the feasibility of incorporating FA within RM activated-GGBS pastes without compromising performance, independent of the curing temperature.

The use of accelerated carbonation enabled all samples to gain significantly higher compressive strengths, as shown in Fig. 6. This increase in strength was due to the formation of carbonate phases such as HMCs and calcite, which filled the available pores and densified the sample microstructure [31]. The strength results of samples over 70 days of carbonation revaled a rapid increase in strength during the first 2 weeks, followed by a slower rate of increase. This reduction in strength gain was associated with the formation of an initial carbonate layer on the sample exterior during the initial stages of carbonation. This layer hindered the further diffusion of $\mathrm{CO}_{2}$ within the sample microstructure at longer durations [31]. Despite their similar starting compressive strengths before carbonation (10-15 MPa), samples cured under ambient conditions $\left(30^{\circ} \mathrm{C}\right)$ demonstrated a higher rate of strength gain than those subjected to HTPC $\left(50^{\circ} \mathrm{C}\right)$. This difference in strength amongst the two groups was mainly obvious during the early stages, after which samples cured under ambient conditions revealed strength values that were 2-4 MPa higher than those of HTPC samples at 70 days of carbonation (20-27 MPa vs. 18-25 MPa). This limitation in the strength development of samples under HTPC conditions could be associated with the rapid precipitation of the reaction products under the elevated temperatures used during the initial curing of these samples, which could have limited their further reaction with $\mathrm{CO}_{2}[21,22]$.

Similar to the trend observed in Fig. 5, the strength development was influenced by the presence of FA, generally reducing with an increase in FA content. However, samples containing $12 \%$ FA revealed similar strengths as the control samples under both conditions $\left(30^{\circ} \mathrm{C}\right.$ and $\left.50^{\circ} \mathrm{C}\right)$ after 70 days of carbonation. Alternatively, an increase in the FA content to $24 \%$ in samples $24 \mathrm{FA}$ and T.24FA led to $\sim 25 \%$ reduction in the strength of both groups at 70 days (20-27 MPa vs. $26 \mathrm{MPa}$ under ambient and 18-23 MPa vs. $25 \mathrm{MPa}$ under HTPC conditions). This reduction could be associated with the higher free water contents of samples incorporating FA, whose low dissolution within the pore space could hinder $\mathrm{CO}_{2}$ diffusion, thereby reducing the formation of HMCs. Furthermore, the lower $\mathrm{CaO}$ content of FA than 
337 GGBS led to decreased formation of calcite under carbonation, which also limited the strength 338 development.

\subsection{XRD}

The XRD patterns of samples at the age of 28 days under ambient and HTPC conditions are 344 presented in Fig. 7(a) and (b), respectively. The broad hump located at around $20-35^{\circ} 2 \theta$ corresponded to unreacted amorphous phases within FA and GGBS. Unhydrated mullite and quartz were also observed in samples containing FA. In line with the findings of previous studies [40], the formation of calcium aluminum silicate hydrate (C-A-S-H, $\mathrm{Ca}\left(\mathrm{Al}_{2} \mathrm{Si}_{6}\right) \mathrm{O}_{16} \cdot 4 \mathrm{H}_{2} \mathrm{O}$, PDF \#00-039-1372), katoite $\left(\mathrm{Ca}_{3} \mathrm{Al}_{2}\left(\mathrm{SiO}_{4}\right)(\mathrm{OH})_{8}, \mathrm{PDF} \# 00-038-0368\right)$, ettringite $\left(\mathrm{Ca}_{6} \mathrm{Al}_{2}\left(\mathrm{SO}_{4}\right)_{3}(\mathrm{OH})_{12} \cdot 26 \mathrm{H}_{2} \mathrm{O}\right.$, PDF \#01-075-7554), magnesium silicate hydrate (M-

S-H, $\quad\left(\mathrm{Mg}_{1.84} \mathrm{Si}_{0.05}\right)\left(\mathrm{Si}_{0.93} \mathrm{Mg}_{0.05}\right) \mathrm{H}_{0.3} \mathrm{O}_{4}, \quad$ PDF \#01-070-6459) and hydrotalcite $\left(\mathrm{Mg}_{6} \mathrm{Al}_{2}\left(\mathrm{CO}_{3}\right)(\mathrm{OH})_{16} \cdot 4 \mathrm{H}_{2} \mathrm{O}\right)$, PDF \#01-014-0191) was observed in the mixes prepared in this study, despite the low dissolution of GGBS and FA, associated with the low alkalinity of the activator. This has also been confirmed by previous studies [41-43], where the presence of crystalline M-S-H and C-(A)-S-H was shown in the XRD patterns. The amorphous humps corresponding to $\mathrm{M}-\mathrm{S}-\mathrm{H}$ at $\sim 35^{\circ}$ and $\sim 60^{\circ} 2 \theta$ could also be present, albeit not distinguishable from the wide humps at $20-40^{\circ} 2 \theta$ and $60-65^{\circ} 2 \theta$. Along with these reaction products, the presence of unhydrated periclase (main peak at $42.9^{\circ} 2 \theta$ ) could also be seen in all patterns, highlighting the incomplete dissolution of RM. A comparison of the residual RM based on the intensity of the internal standard (fluorite at $28.2^{\circ} 2 \theta$ ), revealed the lower intensity of residual RM in the 0FA sample cured under HTPC conditions than those under ambient conditions. This reduction in the peak intensity indicated the accelerated hydration of RM under HTPC conditions, which was in line with the isothermal calorimetry results. An increase in the formation of $\mathrm{C}-(\mathrm{A})-\mathrm{S}-\mathrm{H}$, along with the reduced formation of ettringite, was also observed under HTPC conditions.

Fig. 8 shows the XRD patterns of samples that were cured under ambient and HTPC conditions for 28 days, followed by 56 days under accelerated carbonation. The decrease in intensities of ettringite and hydrotalcite in carbonated samples was attributed to the decalcification of these phases during carbonation. The formation of calcite $\left(\mathrm{CaCO}_{3}, \mathrm{PDF} \# 01-071-3699\right)$, associated 
with the carbonation of portlandite and possibly with the decalcification of ettringite and C-

371 (A)-S-H, was observed in the carbonated samples. A comparison of the residual RM content, based on the intensity of fluorite, revealed the significantly lower intensities of RM in carbonated samples (Fig. 8) than those observed in corresponding samples without carbonation (Fig. 7). This reduction in RM content indicated its transformation into Mg-based carbonation products, which contributed to the higher compressive strengths of the carbonated samples. Accordingly, artinite $\left(\mathrm{Mg}_{2} \mathrm{CO}_{3}(\mathrm{OH})_{2} \cdot 3 \mathrm{H}_{2} \mathrm{O} ;\right.$ PDF \#00-006-0484) and hydromagnesite $\left(4 \mathrm{MgCO}_{3} \cdot \mathrm{Mg}(\mathrm{OH})_{2} \cdot 4 \mathrm{H}_{2} \mathrm{O}\right.$; PDF \#00-025-0513), major HMC phases commonly observed in carbonated RM systems [31, 44, 45], were detected in the XRD patterns of the carbonated samples. When compared with samples cured under ambient conditions (Fig. 8(a)), those subjected to HTPC conditions (Fig. 8(b)) resulted in higher residual RM, explaining their lower transformation of RM into HMCs and thereby lower compressive strengths.

\section{5 $\quad{ }^{27} \mathrm{Al}$ and ${ }^{29} \mathrm{Si}$ MAS NMR}

386 Differently coordinated Al sites appear within distinct ${ }^{27} \mathrm{Al}$ chemical shift ranges in ${ }^{27} \mathrm{Al} \mathrm{NMR}$ (i.e. 80-50 ppm for Al(IV) and 15-0 ppm for Al(VI)). The ${ }^{27} \mathrm{Al}$ MAS NMR spectra of the 0FA, 12FA and 24FA precursor mixes are presented in Fig. 9(a). The ${ }^{27} \mathrm{Al}$ NMR spectra of the 0FA precursor revealed a broad amorphous $\mathrm{Al}(\mathrm{IV})$ resonance, which was indicative of the glasslike slag structure, in agreement with the findings of previous studies on GGBS [46-48]. The inclusion of FA in samples $12 \mathrm{FA}$ and 24FA introduced another small $\mathrm{Al}(\mathrm{VI})$ resonance at $\sim 3$ ppm. This resonance correlated to an octahedral Al component in FA, attributed to mullite. The amorphous $\mathrm{Al}(\mathrm{IV})$ moieties in FA were overshadowed in the NMR spectra by the more populous GGBS Al(IV) component [49, 50].

All of the ${ }^{29} \mathrm{Si}$ spectra in this study were fitted with multiple Gaussian components, providing accurate simulations of the experimental line-shapes, as shown in Fig. 9 and 11. The relative site occupancy of the deconvoluted ${ }^{29} \mathrm{Si}$ components for each of the samples is provided in Table 4. The differing connectivity of Si(IV) moieties in aluminosilicate networks resulted in characteristic ${ }^{29} \mathrm{Si}$ NMR chemical shifts between -60 and $-120 \mathrm{ppm}$. These distinct moieties were labeled $\mathrm{Q}^{n}(m \mathrm{Al})$, where $n$ is the number of $\mathrm{O}$ mediated bonds to adjacent $\mathrm{SiO}_{4} / \mathrm{AlO}_{4}$ units and $m$ is the amount of $\mathrm{Al}$ units involved. 
404 The ${ }^{29}$ Si MAS NMR spectra of the 0FA, 12 FA and 24FA precursor mixes are presented in Fig. 9(b). Corroborating the results of previous studies on GGBS [34, 46, 47, 51], the 0FA precursor material presented two broad amorphous resonances at $\delta_{\text {iso }}$ of $-75 \pm 2$ and $110 \pm 3 \mathrm{ppm}$, relating to the $\mathrm{Q}^{0} / \mathrm{Q}^{1}$ units in the glass-like unhydrated slag and the $\mathrm{Q}^{4}$ environments in amorphous silica $\left(\mathrm{SiO}_{2}\right)$, respectively. The ${ }^{29} \mathrm{Si}$ NMR spectra of the $12 \mathrm{FA}$ and $24 \mathrm{FA}$ precursor materials revealed two additional broad resonances at $\delta_{\text {iso }}$ of $-90 \pm 2$ and $-109 \pm 2 \mathrm{ppm}$, which together represented a distribution of $\mathrm{Q}^{4}$ moieties in FA $[49,52]$. The relative site occupancy of the FA components in samples $0 \mathrm{FA}$ and 12FA was found to be $13.3 \%$ and $29.9 \%$, respectively.

412 Accordingly, these values correlated well with the mass ratios of the Si containing materials in 413 the precursor mixes.

The ${ }^{27} \mathrm{Al}$ MAS NMR spectra of the concrete samples cured under ambient and HTPC conditions for 28 days are presented in Fig. 10(a) and (b), respectively. In comparison with the precursor NMR spectra, these samples presented an altered broad Al(IV) line-shape and two additional sharp $\mathrm{Al}(\mathrm{VI})$ resonances. The changes to the $\mathrm{Al}(\mathrm{IV})$ line-shape was attributable to the tetrahedral $\mathrm{AlO}_{4}$ moieties in the produced C-A-S-H gel, as demonstrated in previous studies $[47,53]$. The two $\mathrm{Al}(\mathrm{VI})$ resonances at 10 and $13 \mathrm{ppm}$ corresponded to $\mathrm{Al}$ in produced hydrotalcite and ettringite phases, respectively [53-55]. The samples subjected to HTPC (Fig. 10(b)), displayed a clear reduction in the site occupancy of the ettringite phase, corroborating the findings of the XRD analysis. Sample T.12FA revealed some sharp features in its ${ }^{27} \mathrm{Al}$ spectrum within the Al(IV) range (Fig. 10(b)) that were not present in any of the other samples, suggesting a more crystalline nature. These findings were in line with the extra peak at $55.72^{\circ}$ $2 \theta$ observed in the XRD patterns (Fig. 7(b)).

The ${ }^{27} \mathrm{Al}$ NMR spectra of the samples subjected to carbonation are presented in Fig. 10(c). The spectra show a complete loss of the ettringite phase in all samples, corroborating the decomposition seen in XRD patterns. The inclusion of FA did not have a significant effect on the ${ }^{27} \mathrm{Al}$ speciation in both the un-carbonated and carbonated samples. The only difference observed was a decrease in the site occupancy of the ettringite phase with increasing FA content. The reduced formation of ettringite in samples including FA could be due to their lower calcium content (Table 1) and the lower dissolution of FA than GGBS (Section 3.2) [25]. 
436 The ${ }^{29} \mathrm{Si}$ MAS NMR spectra of samples cured under ambient and HTPC conditions are 437 presented in Fig. 11(a) and (b), whereas the spectra of carbonated samples following 28 days 438 of ambient curing are presented in Fig. 11(c). All of the ${ }^{29}$ Si NMR spectra in Fig. 11 presented 439 familiar amorphous resonances at -75 and $-110 \mathrm{ppm}$, which were associated with the 440 amorphous $\mathrm{Q}^{0} / \mathrm{Q}^{1}$ and $\mathrm{Q}^{4}$ species present in the precursor GGBS. Samples $12 \mathrm{FA}$ and $24 \mathrm{FA}$ 441 also retained the FA components at -90 and $-109 \mathrm{ppm}$. The combined site occupancy of these 442 FA components (Table 4) remained relatively constant during the curing and carbonation processes, suggesting that FA played a negligible role in the hydration reactions.

The ${ }^{29} \mathrm{Si}$ NMR spectra of samples cured under the ambient and HTPC conditions in Fig. 11(a) and (b) also presented three sharp resonances with a mean $\delta_{\text {iso }}$ of $-79.0,-81.8$ and $-84.7 \mathrm{ppm}$, correlating to crystalline C-(A)-S-H components $\mathrm{Q}^{1}(0 \mathrm{Al}), \mathrm{Q}^{2}(1 \mathrm{Al})$ and $\mathrm{Q}^{2}(0 \mathrm{Al})$, respectively $[46,47]$. These were accompanied with an amorphous product component (-83 ppm) relating to less crystalline $\mathrm{C}-(\mathrm{A})-\mathrm{S}-\mathrm{H}$ phases [5]. The relative intensities of these ${ }^{29} \mathrm{Si}$ components (Table 4) were lower for samples subjected to HTPC than those cured under ambient conditions, with significant reductions in the $\mathrm{Q}^{1}(0 \mathrm{Al})$ and $\mathrm{Q}^{2}(1 \mathrm{Al})$ species. This suggested the lower dissolution of GGBS within samples subjected to HTPC, which could also explain the slightly lower compressive strengths of these samples in comparison to those cured under ambient conditions.

The inclusion of FA could have contributed to the formation of crystalline C-(A)-S-H components in both sets of curing conditions. Accordingly, the total site occupancy of the crystalline components markedly increased with increasing FA content under ambient conditions. The inclusion of FA could stimulate the dispersion of dissolved silica and enhance the addition of silica chains with crystallized regions to C-(A)-S-H layers. The changing product concentrations in samples with different FA contents can be compared more clearly by ignoring the site occupancy of the unreacting FA components (i.e. calculating the total site occupancy of the crystalline components without including the percentage of Si in FA), revealing the tripling of the crystalline site occupancy from $3.6 \%$ for sample $0 \mathrm{FA}$ to $10 \%$ for sample 24FA (i.e. $6.9 /(1-0.308)=10 \%$ ). A less pronounced increase (i.e. $3.5 \%$ for T.0FA to $6.1 \%$ for T.24FA) was observed for corresponding samples subjected to HTPC conditions. However, this observed increase in the C-(A)-S-H components did not increase the compressive strength of the samples enough to offset the negative effect of the reduction in the content of GGBS with the introduction of FA. 
471 The carbonation process resulted in the complete loss of the crystalline $\mathrm{Q}^{1}(0 \mathrm{Al})$ and $\mathrm{Q}^{2}(1 \mathrm{Al})$ 472 phases, as shown by Fig. 11(c), revealing the degradation of C-(A)-S-H gel due to 473 decalcification by $\mathrm{CO}_{2}$. A new component at $\delta_{\text {iso }}$ of $-91.9 \pm 0.5$ ppm was observed in each of the 474 carbonated samples, which was assigned as $\mathrm{Q}^{4}(3 \mathrm{Al})$ species in previous studies [56]. These 475 species provided evidence for the formation of a highly cross-linked aluminosilicate type gel, 476 resulting from the breakdown of the C-(A)-S-H network. Furthermore, the carbonation process 477 led to an increase in the intensity of the broad resonance at $-75 \mathrm{ppm}$ due to the production of 478 amorphous monomeric/dimeric $\left(\mathrm{Q}^{0} / \mathrm{Q}^{1}\right)$ silicate units during the decomposition of $\mathrm{C}-(\mathrm{A})-\mathrm{S}-\mathrm{H}$ phases, which was in line with earlier findings [56].

480

481

482

\subsection{TG-DTG}

483

TG-DTG curves of samples cured under ambient and HTPC conditions for 28 days are presented in Fig. 12(a) and (b), respectively. Despite accelerating the hydration of RM at early ages, subjecting the samples to HTPC conditions did not result in an increase in the overall mass loss. This lack of increase in the mass loss corresponding to the presence of hydrate phases, highlighted the inability of HTPC in enhancing the hydration reaction, explaining the similar compressive strengths of these samples to those cured under ambient conditions.

Fig. 13 shows the TG-DTG curves of samples after 28 days of ambient curing, followed by 56 days of carbonation. Consistent with the XRD results, the formation of HMCs and calcite during the carbonation process led to higher mass losses within the carbonated samples (Fig. 13) than those observed in corresponding samples cured under ambient or HTPC conditions (Fig. 12). The increased mass loss of these samples indicated the additional formation of HMCs and calcite as a result of the reaction between $\mathrm{Mg}$ - and $\mathrm{Ca}-$ phases and dissolved $\mathrm{CO}_{2}$.

497 Accordingly, the following three steps of decomposition were detected from the DTG curves:

499 (i) The peak at $\sim 90^{\circ} \mathrm{C}$ corresponded to the evaporation of water bonded to the gel structure 500 (i.e. C-(A)-S-H, M-S-H and ettringite) $[16,57,58]$ while the shoulder at $\sim 200^{\circ} \mathrm{C}$ was assigned 501 to the evaporation of water within hydrotalcite and HMCs [5, 59]. 
503 (ii) The peak at $\sim 390^{\circ} \mathrm{C}$ was assigned to the decomposition of hydrotalcite and 504 dehydroxylation of portlandite in non-carbonated samples [11,59]. This peak was shifted to $\sim 420^{\circ} \mathrm{C}$ in the carbonated samples [60]. Furthermore, the peak/shoulder at $\sim 490^{\circ} \mathrm{C}$, observed in the carbonated samples, was attributed to the dehydroxylation of HMCs [30, 61].

(iii) The peak at $\sim 700^{\circ} \mathrm{C}$ was associated with the decarbonation of carbonates (e.g. calcite and HMCs) $[11,30,59,61]$.

511 DTG curves were deconvoluted into Gaussian components representing the decomposition of each phase by using the Origin software. The calculation of the mass loss corresponding to the decarbonation process was taken as the area of the deconvoluted component corresponding to decarbonation, which ranged between $\sim 550-600^{\circ} \mathrm{C}$ and $750-800^{\circ} \mathrm{C}$. The total and individual mass loss values corresponding to the decomposition of the hydrate and carbonate phases, obtained by calculating the area of their deconvoluted DTG curves via the Origin software, are presented in Table 5. In line with the XRD and NMR results, the lower formation of ettringite and hydrotalcite in samples subjected to HTPC conditions led to lower mass lossess associated with the dehydration of these phases than those cured under ambient conditions. Despite the lower formation of hydrotalcite, samples subjected to HTCP indicated higher $\mathrm{CO}_{2}$ absorption in the formation of HMCs and calcite than those cured under ambient conditions $(1.8-3.8 \% \mathrm{vs}$. 3.1-4\%). Overall, the use of HTPC led to slightly lower total mass loss values than ambient curing (13-13.2\% vs. 13.8-14.7\%), explaining the limited hydration presented by the former condition.

Subjecting the samples to carbonation conditions stimulated the dissolution of RM, portlandite and possibly $\mathrm{C}-(\mathrm{A})-\mathrm{S}-\mathrm{H}$, thereby facilitating the formation of HMCs and calcite. Accordingly, an increase in the mass loss corresponding to decarbonation from 1.8-3.8\% (after 28 days of ambient curing) to $6.7-7.9 \%$ (after 28 days of ambient curing and 56 days of carbonation); and from $3.1-4.0 \%$ (after 28 days of HTPC) to $4.9-6.6 \%$ (after 28 days of HTPC and 56 days of carbonation) was observed when samples were exposed to carbonation. The high crystallinity of brucite that formed under HTPC led to the lower absorption of $\mathrm{CO}_{2}$ within these samples than those cured under ambient conditions [21]. The additional formation of carbonate phases such as HMCs and calcite also translated into a significant increase in the total mass loss revealed by carbonated samples (20.5-21.9\% for samples after 28 days of ambient curing and 56 days of carbonation; and 15.9-18.5\% for samples after 28 days of HTPC and 56 days of 
carbonation) in comparison to non-carbonated samples (13.8-14.7\% for samples cured under ambient conditions and $13.0-13.2 \%$ for samples subjected to HTPC). Within the carbonated samples, a decline in the total mass loss was overved with an increase in FA content, which could explain the corresponding reduction in the strength of these samples. Accordingly, as the FA content increased from $0 \%$ in sample $0 \mathrm{FA}$ to $24 \%$ in sample $24 \mathrm{FA}$, a $\sim 40 \%$ reduction in strength was observed at 56 days of carbonation (Fig. 6). This decline in total mass loss could be attributed to the lower formation of ettringite, as also revealed earlier by NMR, and the lower $\mathrm{CO}_{2}$ absorption within samples including high contents of FA.

The amount of $\mathrm{CO}_{2}$ sequestered $\left(\mathrm{S}_{\mathrm{CO}}\right)$ by each concrete sample during the carbonation process was calculated by Equation 1, where $R_{s p}$ represented the mass of the residual sample (i.e. the final mass at $900^{\circ} \mathrm{C}$ ), and $D_{\mathrm{CO} 2}^{A}$ and $D_{\mathrm{CO} 2}^{A C}$ represented the mass loss associated with decarbonation after ambient and the accelerated carbonation curing, respectively. In this respect, $D_{\mathrm{CO} 2}^{A}$ and $D_{\mathrm{CO} 2}^{A C}$ included the $\mathrm{CO}_{2}$ released from the decomposition of all carbonate phases (e.g. HMCs and calcite). Since the carbonation rate of RM was much more pronounced than that of ettringite and C-(A)-S-H (i.e. also reflected by the higher decrease in the intensities of $\mathrm{RM}$ peaks than those of ettringite and $\mathrm{C}-(\mathrm{A})-\mathrm{S}-\mathrm{H})$, the $\mathrm{CO}_{2}$ sequestration was assumed to be mainly associated with the carbonation of RM.

$$
S_{\mathrm{CO} 2}=\frac{D_{\mathrm{CO} 2}^{A C}-D_{C O 2}^{A}}{R_{S p}} 100 \%
$$

As seen in Table 5, the highest $\mathrm{CO}_{2}$ sequestration was revealed by sample $12 \mathrm{FA}(35.6 \%)$, corresponding to around $44.5 \mathrm{~kg} \mathrm{CO}_{2}$ in $1 \mathrm{~m}^{3}$ of concrete, which contained $125 \mathrm{~kg} \mathrm{RM}$. Since the $\mathrm{CO}_{2}$ emissions associated with the production of 1 ton of $\mathrm{RM}$ cement is around 1.1 ton [62], the net $\mathrm{CO}_{2}$ emissions in $1 \mathrm{~m}^{3}$ of concrete utilizing the same binder composition as sample $12 \mathrm{FA}$ is around $93 \mathrm{~kg}$ (i.e. $1.1 \times 125 \mathrm{~kg}$ (the amount of $\mathrm{CO}_{2}$ released from the production of 125 $\mathrm{kg} \mathrm{RM})-44.5 \mathrm{~kg}$ (the amount of $\mathrm{CO}_{2}$ sequrestrated via carbonation)). On the other hand, the approximate $\mathrm{CO}_{2}$ emissions of a concrete sample involving the use of PC with an equivalent performance is around $198 \mathrm{~kg} / \mathrm{m}^{3}$ (i.e. $0.66 \times 300 \mathrm{~kg}$ (the amount of $\mathrm{CO}_{2}$ released from the production of $300 \mathrm{~kg}$ PC, which was calculated in accordance with the ACI 211.1-91 standard) $[63,64])$. Therefore, the use of carbonation curing for the long-term sequestration of $\mathrm{CO}_{2}$ in concrete products do not only enable the reduction of overall $\mathrm{CO}_{2}$ emissions associated with 
cement production (i.e. especially if $\mathrm{CO}_{2}$ is sourced from a waste/industrial outlet), but also facilitate the use of RM and various other by-products in the proposed formulations.

\subsection{Microstructural analysis}

The microstructures of samples cured under ambient conditions for 28 days are shown in Fig. 14; whereas those cured under HTPC for 28 days are shown in Fig. 15. Ambient curing and HTPC revealed a porous microstructure dominated by unhydrated particles in the 0FA and T.0FA samples (Fig. 14(a) and Fig. 15(a)). Unhydrated FA with a diameter of $\sim 2-6 \mu \mathrm{m}$ was observed in samples 12FA, 24FA and T.24FA, along with the formation of needle-like ettringite. The ball-bearing effect introduced by the spherical nature of these FA particles that filled the initially available pores could explain the improvements in workability, as well as the denser microstructures of samples 12FA, 24FA, T.12FA and T.24FA in comparison to samples OFA and T.OFA. The formation of this denser microstructure could hinder $\mathrm{CO}_{2}$ diffusion within these samples, thereby leading to a lower carbonation degree than samples 0FA and T.0FA, which was in line with the strength, XRD and TGA results.

The formation of carbonate phases such as HMCs during carbonation contributed to the densification of the microstructures of carbonated samples (Fig. 16), which were much more compact than the relatively porous microstructures observed under ambient curing (Fig. 14). A more detailed look into the microstructures of carbonated samples revealed the formation of artinite layers including needle-like crystals with a dimeter of $\sim 0.2-0.3 \mu \mathrm{m}$ and length of $\sim 3-6$ $\mu \mathrm{m}$ within sample 0FA (Fig. 17(a)). Alternatively, the formation of hydromagnesite crystals with a diameter of $\sim 3-4 \mu \mathrm{m}$ was observed in samples 12FA and 24FA (Fig. 17(b) and (c)), highlighting the variations in carbonate formations in line with the binder composition. The formation of these carbonate phases and the continuous network they established could explain the development of strength observed during carbonation. Accordingly, the pore filling effect and the binding strength provided via the interlocking of large carbonate crystals corresponded to the improved performance of the prepared samples after the carbonation process. In line with XRD and TGA results, SEM images indicated the limited formation of HMCs in samples cured under HTPC when compared to those cured under ambient conditions (Fig. 18 vs. Fig. 17). 
This study focused on the development of sustainable binders involving the use of RM activated-GGBS that included $12 \%$ and $24 \%$ FA. The performance of these binders was aimed to be improved by (i) enhancing the hydration of RM and the dissolution of GGBS and FA via the adjustment of the curing temperature and (ii) conversion of the unreacted phases and hydrates into carbonates with the ability to provide strength via the sequestration of $\mathrm{CO}_{2}$. The findings revealed the following conclusions:

611

612 FA did not play a direct role in the hydration reaction and the partial replacement of GGBS by 613 FA led to longer initial setting times and lower strengths. Alternatively, the inclusion of FA 614 stimulated the formation of crystalline C-(A)-S-H, but restrained the production of ettringite. 615 Coupled with the enhancement in sample workability and pore filling effect, the use of FA led 616 to denser microstructures, which resulted in lower $\mathrm{CO}_{2}$ diffusions and thereby reduced the 617 formation of carbonate phases. This reduction in reaction degrees translated into lower 618 compressive strengths when the FA content increased to 24\%. Alternatively, the use of $12 \%$ 619 FA in RM activated-GGBS samples resulted in comparable strengths to those of RM activated620 GGBS samples, highlighting the feasibility of incorporating FA within RM activated-GGBS samples without compromising performance.

623 The use of HTPC as a part of the curing process significantly accelerated the hydration of $\mathrm{MgO}$ and produced high initial strengths during the first week of curing. However, the rapid precipitation of brucite hindered the dissolution of GGBS and FA and the consequent formation of hydration products. These limitations in reaction mechanisms were reflected as decreased formation of reaction products and thereby lower strengths at longer curing durations when compared with samples cured under ambient conditions.

630 The sequestration of $\mathrm{CO}_{2}$ by subjecting the samples to accelerated carbonation enabled the transformation of unreacted phases and hydrates into dense carbonate phases such as HMCs (i.e. artinite and hydromagnesite) and calcite. These carbonation conditions translated into rapid strength gain and microstructural development within the first 14 days. The carbonation

634 process led to a reduction in porosity and provided a binding network facilitated by the 635 formation of carbonate phases, thereby improving sample performance by up to $\sim 100 \%$, despite the degradation of certain phases (i.e. ettringite and C-(A)-S-H). 
638 Overall, the obtained results indicated that the use of carbonation curing for the long-term 639 sequestration of $\mathrm{CO}_{2}$ in concrete products could enable the reduction of $\mathrm{CO}_{2}$ emissions 640 associated with cement production (i.e. especially if $\mathrm{CO}_{2}$ is sourced from a waste/industrial 641 outlet), and facilitate the use of RM and various other by-products in the proposed formulations, 642 thereby reducing the consumption of natural resources in the production cement. Future studies 643 will involve a detailed assessment of the changes in the pore structure during the hydration and 644 carbonation processes to investigate the microstructural evolution of RM-activated alternative 645 binders under carbonation conditions.

646

647

648 Acknowledgment

649

650 The authors would like to acknowledge the financial support from the Singapore MOE 651 Academic Research Fund Tier 1 (RG 95/16) and the assistance of Mr. Douglas Kieo Yong 652 Qiang for the completion of this research project. 
[1] D.L. Chandler, Researchers have created emissions-free cement, Worl Economic Forum 2019.

657 [2] P. Li, J. Tang, Y.I.N. Bai, X. Chen, J. Chen, Experimental study on the pH for activating ground granulated blast-furnace slag activity at different temperatures, Sādhanā 44(10) (2019) 213.

660 [3] S.-D. Wang, K.L. Scrivener, Hydration products of alkali activated slag cement, Cement and Concrete Research 25(3) (1995) 561-571. granulated blast furnace slag, Journal of Materials Science 35(1) (2000) 249-257.

664 [5] N.T. Dung, T.J.N. Hooper, C. Unluer, Accelerating the reaction kinetics and improving the performance of Na2CO3-activated GGBS mixes, Cement and Concrete Research 126 (2019). [6] D. Krizan, B. Zivanovic, Effects of dosage and modulus of water glass on early hydration of alkali-slag cements, Cement and Concrete Research 32(8) (2002) 1181-1188. activator nature, Advances in Cement Research 13(3) (2001) 115-121. [8] M. Palacios, F. Puertas, Effect of shrinkage-reducing admixtures on the properties of alkaliactivated slag mortars and pastes, Cement and Concrete Research 37(5) (2007) 691-702. [9] T. Bakharev, J.G. Sanjayan, Y.B. Cheng, Resistance of alkali-activated slag concrete to alkali-aggregate reaction, Cement and Concrete Research 31(2) (2001) 331-334. [10] F. Jin, K. Gu, A. Al-Tabbaa, Strength and drying shrinkage of reactive MgO modified alkali-activated slag paste, Construction and Building Materials 51 (2014) 395-404. ground granulated blastfurnace slag paste, Cement and Concrete Composites 57 (2015) 8-16. [12] B. Lu, W. Zhu, Y. Weng, Z. Liu, E.-H. Yang, K.F. Leong, M.J. Tan, T.N. Wong, S. Qian, Study of MgO-activated slag as a cementless material for sustainable spray-based 3D printing, Journal of Cleaner Production 258 (2020) 120671. [13] Y. Yi, M. Liska, A. Al-Tabbaa, Properties and microstructure of GGBS-magnesia pastes, Advances in Cement Research 26(2) (2014) 114-122. immobilisation of lead and zinc, Chemosphere 117 (2014) 285-294. granulated blast-furnace slag, Construction and Building Materials 192 (2018) 403-415. 
[16] F. Jin, K. Gu, A. Abdollahzadeh, A. Al-Tabbaa, Effects of Different Reactive MgOs on the Hydration of MgO-Activated GGBS Paste, Journal of Materials in Civil Engineering 27(7) (2015) B4014001.

690 [17] D. Wang, X. Gao, R. Wang, S. Larsson, M. Benzerzour, Elevated curing temperatureassociated strength and mechanisms of reactive $\mathrm{MgO}$-activated industrial by-products solidified soils, Marine Georesources \& Geotechnology (2019) 1-13.

693 [18] Y. Yi, M. Liska, A. Al-Tabbaa, Initial Investigation into the Use of GGBS-MgO in Soil 694 Stabilisation, Grouting and Deep Mixing 20122012, pp. 444-453.

[19] Y. Yi, M. Liska, A. Al-Tabbaa, Properties of Two Model Soils Stabilized with Different

Blends and Contents of GGBS, MgO, Lime, and PC, Journal of Materials in Civil Engineering 26(2) (2014) 267-274.

698 [20] Y. Yi, C. Li, S. Liu, A. Al-Tabbaa, Resistance of MgO-GGBS and CS-GGBS stabilised 699 marine soft clays to sodium sulfate attack, Géotechnique 64(8) (2014) 673-679.

700 [21] N.T. Dung, C. Unluer, Carbonated MgO concrete with improved performance: The influence of temperature and hydration agent on hydration, carbonation and strength gain, Cement and Concrete Composites 82 (2017) 152-164.

703

[22] L.F. Amaral, I.R. Oliveira, R. Salomão, E. Frollini, V.C. Pandolfelli, Temperature and common-ion effect on magnesium oxide $(\mathrm{MgO})$ hydration, Ceramics International 36(3) (2010) 1047-1054.

[23] J.J. Thomas, S. Musso, I. Prestini, Kinetics and Activation Energy of Magnesium Oxide Hydration, Journal of the American Ceramic Society 97(1) (2014) 275-282.

[24] T. Yang, H. Zhu, Z. Zhang, X. Gao, C. Zhang, Q. Wu, Effect of fly ash microsphere on the rheology and microstructure of alkali-activated fly ash/slag pastes, Cement and Concrete Research 109 (2018) 198-207.

711 [25] Z. Sun, A. Vollpracht, Isothermal calorimetry and in-situ XRD study of the $\mathrm{NaOH}$ 712 activated fly ash, metakaolin and slag, Cement and Concrete Research 103 (2018) 110-122.

713 [26] I. Wilińska, B. Pacewska, Influence of selected activating methods on hydration processes

714 of mixtures containing high and very high amount of fly ash, Journal of Thermal Analysis and 715 Calorimetry 133(1) (2018) 823-843.

716 [27] N. Cristelo, P. Tavares, E. Lucas, T. Miranda, D. Oliveira, Quantitative and qualitative 717 assessment of the amorphous phase of a Class F fly ash dissolved during alkali activation 718 reactions - Effect of mechanical activation, solution concentration and temperature, 719 Composites Part B: Engineering 103 (2016) 1-14. 
[28] Q. Wang, D. Wang, H. Chen, The role of fly ash microsphere in the microstructure and macroscopic properties of high-strength concrete, Cement and Concrete Composites 83 (2017) 125-137.

[29] Y. Li, A.K.H. Kwan, Ternary blending of cement with fly ash microsphere and condensed silica fume to improve the performance of mortar, Cement and Concrete Composites 49 (2014) 26-35.

[30] N.T. Dung, C. Unluer, Influence of accelerated hydration and carbonation on the performance of reactive magnesium oxide concrete, Advances in Cement Research 32(2) (2018) 13.

[31] N.T. Dung, A. Lesimple, R. Hay, K. Celik, C. Unluer, Formation of carbonate phases and their effect on the performance of reactive $\mathrm{MgO}$ cement formulations, Cement and Concrete Research 125 (2019) 105894. [32] G. Mármol, L. Mattoso, A.C. Correa, C.A. Fioroni, H. Savastano, Influence of cellulose pulp on the hydration followed by fast carbonation of $\mathrm{MgO}$-based binders, Journal of $\mathrm{CO} 2$ Utilization 41 (2020) 101236.

[33] N.T. Dung, R. Hay, A. Lesimple, K. Celik, C. Unluer, Influence of CO2 concentration on the performance of $\mathrm{MgO}$ cement mixes, Cement and Concrete Composites 115 (2021) 103826. [34] N.T. Dung, T.J.N. Hooper, C. Unluer, Improving the carbonation resistance of Na2CO3activated slag mixes via the use of reactive $\mathrm{MgO}$ and nucleation seeding, Cement and Concrete Composites 115 (2021) 103832.

740 [35] S. Ma, A.H. Akca, D. Esposito, S. Kawashima, Influence of aqueous carbonate species on hydration and carbonation of reactive $\mathrm{MgO}$ cement, Journal of CO2 Utilization 41 (2020) 101260.

[36] W. Li, Y. Yi, Stabilization/solidification of lead- and zinc-contaminated soils using MgO and CO2, Journal of CO2 Utilization 33 (2019) 215-221.

[37] C. Unluer, A. Al-Tabbaa, Enhancing the carbonation of $\mathrm{MgO}$ cement porous blocks through improved curing conditions, Cement and Concrete Research 59 (2014) 55-65. [38] A.C. C01, Standard Test Method for Flow of Hydraulic Cement Mortar, ASTM C1437 15, ASTM International, 100 Barr Harbor Drive, PO Box C700, West Conshohocken, PA 19428-2959, United States, 2015.

[39] ASTM C191 -13, Standard Test Methods for Time of Setting of Hydraulic Cement by Vicat Needle, ASTM Committee C01, PO Box C700, West Conshohocken, PA 19428-2959. United States, 2013, p. 8. 
753

754

755

756

757

758

759

760

761

762

763

764

765

766

767

768

769

770

771

772

773

774

775

776

777

778

779

780

781

782

783

784

785

[40] W. Chen, H.J.H. Brouwers, The hydration of slag, part 1: reaction models for alkaliactivated slag, Journal of Materials Science 42(2) (2006) 428-443.

[41] B. Lothenbach, D. Nied, E. L'Hôpital, G. Achiedo, A. Dauzères, Magnesium and calcium silicate hydrates, Cement and Concrete Research 77 (2015) 60-68.

[42] E. Bernard, B. Lothenbach, C. Cau-Dit-Coumes, C. Chlique, A. Dauzères, I. Pochard, Magnesium and calcium silicate hydrates, Part I: Investigation of the possible magnesium incorporation in calcium silicate hydrate $(\mathrm{C}-\mathrm{S}-\mathrm{H})$ and of the calcium in magnesium silicate hydrate (M-S-H), Applied Geochemistry 89 (2018) 229-242.

[43] C. Roosz, P. Vieillard, P. Blanc, S. Gaboreau, H. Gailhanou, D. Braithwaite, V. Montouillout, R. Denoyel, P. Henocq, B. Madé, Thermodynamic properties of C-S-H, C-A-S$\mathrm{H}$ and M-S-H phases: Results from direct measurements and predictive modelling, Applied Geochemistry 92 (2018) 140-156.

[44] M. Liska, A. Al-Tabbaa, Ultra-green construction: reactive magnesia masonry products, Proceedings of the Institution of Civil Engineers - Waste and Resource Management 162(4) (2009) 185-196.

[45] R. Hay, K. Celik, Accelerated carbonation of reactive magnesium oxide cement (RMC)based composite with supercritical carbon dioxide ( $\mathrm{scCO} 2$ ), Journal of Cleaner Production 248 (2020) 119282.

[46] J. Schneider, M.A. Cincotto, H. Panepucci, 29Si and 27Al high-resolution NMR characterization of calcium silicate hydrate phases in activated blast-furnace slag pastes, Cement and Concrete Research 31(7) (2001) 993-1001.

[47] S.-D. Wang, K.L. Scrivener, 29Si and 27Al NMR study of alkali-activated slag, Cement and Concrete Research 33(5) (2003) 769-774.

[48] P.J. Schilling, L.G. Butler, A. Roy, H.C. Eaton, 29Si and 27Al MAS-NMR of NaOHActivated Blast-Furnace Slag, Journal of the American Ceramic Society 77(9) (1994) 23632368.

[49] X. Gao, Q.L. Yu, H.J.H. Brouwers, Apply 29Si, 27Al MAS NMR and selective dissolution in identifying the reaction degree of alkali activated slag-fly ash composites, Ceramics International 43(15) (2017) 12408-12419.

[50] M. Criado, W. Aperador, I. Sobrados, Microstructural and Mechanical Properties of Alkali Activated Colombian Raw Materials, Materials 9(3) (2016) 158.

[51] R. Tänzer, A. Buchwald, D. Stephan, Effect of slag chemistry on the hydration of alkaliactivated blast-furnace slag, Materials and Structures 48(3) (2015) 629-641. 
[52] Á. Palomo, S. Alonso, A. Fernandez-Jiménez, I. Sobrados, J. Sanz, Alkaline Activation of Fly Ashes: NMR Study of the Reaction Products, Journal of the American Ceramic Society 87(6) (2004) 1141-1145.

[53] G. Le Saoût, M. Ben Haha, F. Winnefeld, B. Lothenbach, Hydration Degree of AlkaliActivated Slags: A 29Si NMR Study, Journal of the American Ceramic Society 94(12) (2011) 4541-4547.

792 [54] X. Pardal, F. Brunet, T. Charpentier, I. Pochard, A. Nonat, 27Al and 29Si Solid-State 793 NMR Characterization of Calcium-Aluminosilicate-Hydrate, Inorganic Chemistry 51(3) (2012) 1827-1836.

795

[55] J. Skibsted, M.T. Pedersen, J. Holzinger, Resolution of the Two Aluminum Sites in Ettringite by 27Al MAS and MQMAS NMR at Very High Magnetic Field (22.3 T), The Journal of Physical Chemistry C 121(7) (2017) 4011-4017. [56] S.A. Bernal, R. San Nicolas, R.J. Myers, R. Mejía de Gutiérrez, F. Puertas, J.S.J. van Deventer, J.L. Provis, $\mathrm{MgO}$ content of slag controls phase evolution and structural changes induced by accelerated carbonation in alkali-activated binders, Cement and Concrete Research 57(Supplement C) (2014) 33-43.

802

[57] O. Burciaga-Díaz, I. Betancourt-Castillo, Characterization of novel blast-furnace slag cement pastes and mortars activated with a reactive mixture of $\mathrm{MgO}-\mathrm{NaOH}, \mathrm{Cement}$ and Concrete Research 105 (2018) 54-63.

[58] N.T. Dung, T.-P. Chang, C.-T. Chen, Circulating Fluidized Bed Combustion Fly-AshActivated Slag Concrete as Novel Construction Material, Materials Journal 112(1). [59] L. Pesic, S. Salipurovic, V. Markovic, D. Vucelic, W. Kagunya, W. Jones, Thermal characteristics of a synthetic hydrotalcite-like material, Journal of Materials Chemistry 2(10) (1992) 1069-1073.

810 [60] M. Muthu, S. Kumar, E.H. Yang, C. Unluer, Degradation of carbonated reactive MgO811 based concrete exposed to nitric acid, Journal of CO2 Utilization 36 (2020) 210-219.

812 [61] N.T. Dung, C. Unluer, Improving the Carbonation of reactive MgO cement concrete via 813 the use of $\mathrm{NaHCO}_{3}$ and $\mathrm{NaCl}$, Journal of Materials in Civil Engineering 30(12) (2018) 81404018320.

815 [62] S. Ruan, C. Unluer, Comparative life cycle assessment of reactive MgO and Portland 816 cement production, Journal of Cleaner Production 137 (2016) 258-273.

817 [63] ACI Committee 211, Standard Practice for Selecting Proportions for Normal, 818 Heavyweight and Mass Concrete, ACI 211.1-91, American Concrete Institute, Farmington 819 Hills, Michigan, 1991. 
820 [64] World Business Council for Sustainable Development (WBCSD) Cement Sustainability 821 Initiative (CSI), Cement industry energy and CO2 performance - Getting the Numbers Right 822 (GNR), 2009.

823 [65] World Business Council for Sustainable Development (WBCSD) Cement Sustainability 824 Initiative (CSI), Cement industry energy and CO2 performance - Getting the Numbers Right 825 (GNR), (2009).

826

827 


\section{List of Tables}

Table 1 Chemical composition and physical properties of RM, GGBS and FA.

\begin{tabular}{|c|c|c|c|c|c|c|c|c|c|c|c|}
\hline \multicolumn{10}{|c|}{ Chemical composition (\%) } & \multicolumn{2}{|c|}{ Physical properties } \\
\hline & $\mathrm{MgO}$ & $\mathrm{SiO}_{2}$ & $\mathrm{CaO}$ & $\mathrm{Al}_{2} \mathrm{O}_{3}$ & $\mathrm{Fe}_{2} \mathrm{O}_{3}$ & $\mathrm{R}_{2} \mathrm{O}$ & $\mathrm{SO}_{3}$ & LOI & Others & $\begin{array}{l}\text { Specific } \\
\text { gravity } \\
\left(\mathrm{g} / \mathrm{cm}^{3}\right)\end{array}$ & $\begin{array}{c}\text { Specific } \\
\text { surface } \\
\text { area } \\
\left(\mathrm{m}^{2} / \mathrm{g}\right)\end{array}$ \\
\hline $\mathrm{RM}$ & $>91.5$ & 2.0 & 1.6 & 1.0 & - & - & - & 4.0 & - & 3.0 & 16.3 \\
\hline GGBS & 6.9 & 27.2 & 45.3 & 12.6 & 0.3 & 3.3 & 3.9 & 0.9 & 0.5 & - & - \\
\hline FA & 0.8 & 58.6 & 1.2 & 30.4 & 4.7 & 3.5 & - & 0.6 & 0.2 & - & - \\
\hline
\end{tabular}


Table 2 Mix designs of concrete samples prepared in this study.

\begin{tabular}{lcccccccc}
\hline Mix & RM & GGBS & FA & \multicolumn{5}{c}{ Mixture proportion (kg) } \\
\cline { 7 - 9 } & $($ wt.\% $)$ & $($ wt.\% $)$ & $($ wt. $\%)$ & RM & GGBS & FA & Aggregates & Water \\
\hline 0FA & & 80 & 0 & & 500 & 0 & & \\
12FA & 20 & 68 & 12 & 125 & 425 & 75 & 1200 & 312.5 \\
24FA & & 56 & 24 & & 350 & 150 & & \\
\hline
\end{tabular}


Table 3 Fresh properties of RM activated-GGBS-FA pastes.

\begin{tabular}{lcccc}
\hline Mix & $\mathrm{pH}$ & Flow (\%) & Initial setting (h) & Final setting (h) \\
\hline 0FA & 12 & 163 & 7.75 & 17.5 \\
12FA & 12.07 & 190 & 10.25 & 16.5 \\
24FA & 11.97 & 201 & 10.75 & 18.5 \\
\hline
\end{tabular}


Table 4 The relative intensity of the simulated components in the ${ }^{29} \mathrm{Si}$ spectra of the precursor mixtures, samples cured under ambient and HTPC conditions for 28 days, and samples after 28 days of ambient curing followed by 56 days of carbonation. The relative intensities of each site were determined via line-shape simulation using DMFIT [40].

\begin{tabular}{|c|c|c|c|c|c|c|c|c|c|c|c|}
\hline \multirow{4}{*}{$\begin{array}{l}\text { Curing } \\
\text { condition }\end{array}$} & \multirow{4}{*}{ Mix } & \multicolumn{10}{|c|}{${ }^{29} \mathrm{Si}$ NMR relative intensity } \\
\hline & & \multirow{3}{*}{$\begin{array}{c}\text { Amorphous } \\
\mathrm{Q}^{0} / \mathrm{Q}^{1}\end{array}$} & \multirow{3}{*}{$\begin{array}{c}\text { Amorphous } \\
\mathrm{Q}^{4}\end{array}$} & \multirow{3}{*}{$\begin{array}{l}\text { Fly } \\
\text { ash } \\
Q^{4}\end{array}$} & \multicolumn{5}{|c|}{ Crystalline products } & \multirow{3}{*}{$\begin{array}{c}\text { Amorphous } \\
\text { C-S-H }\end{array}$} & \multirow{3}{*}{$\begin{array}{l}\text { Total } \\
\text { C-S-H }\end{array}$} \\
\hline & & & & & & & & & & & \\
\hline & & & & & $\mathrm{Q}^{1}$ & $\mathrm{Q}^{2}(1 \mathrm{Al})$ & $\mathrm{Q}^{2}$ & $\mathrm{Q}^{4}(3 \mathrm{Al})$ & Total & & \\
\hline \multirow{3}{*}{ Precursors } & OFA & 77.7 & 22.3 & 0.0 & 0.0 & 0.0 & 0.0 & 0.0 & 0.0 & 0.0 & 0.0 \\
\hline & $12 \mathrm{FA}$ & 68.1 & 18.6 & 13.3 & 0.0 & 0.0 & 0.0 & 0.0 & 0.0 & 0.0 & 0.0 \\
\hline & $24 \mathrm{FA}$ & 54.6 & 15.5 & 29.9 & 0.0 & 0.0 & 0.0 & 0.0 & 0.0 & 0.0 & 0.0 \\
\hline \multirow{3}{*}{ Ambient } & 0FA & 37.3 & 23.0 & 0.0 & 0.4 & 0.5 & 2.7 & 0.0 & 3.6 & 36.2 & 39.7 \\
\hline & $12 \mathrm{FA}$ & 34.3 & 19.9 & 12.9 & 0.7 & 2.2 & 2.7 & 0.0 & 5.6 & 27.3 & 32.9 \\
\hline & $24 \mathrm{FA}$ & 24.4 & 15.7 & 30.8 & 0.7 & 1.6 & 4.7 & 0.0 & 6.9 & 22.2 & 29.1 \\
\hline \multirow{6}{*}{ НTPC } & T.0F & 44.0 & 22.6 & & & & & & & & \\
\hline & A & & & 0.0 & 0.2 & 0.3 & 3.0 & 0.0 & 3.5 & 29.9 & 33.4 \\
\hline & $\mathrm{T} .12 \mathrm{~F}$ & 37.7 & 19.6 & & & & & & & & \\
\hline & A & & & 12.7 & 0.2 & 0.3 & 3.4 & 0.0 & 3.9 & 26.1 & 30.0 \\
\hline & $\mathrm{T} .24 \mathrm{~F}$ & 29.9 & 15.5 & & & & & & & & \\
\hline & A & & & 30.7 & 0.2 & 0.4 & 3.7 & 0.0 & 4.2 & 19.7 & 23.9 \\
\hline \multirow{3}{*}{$\begin{array}{l}\text { Ambient } \\
\text { and } \\
\text { carbonation }\end{array}$} & 0FA & 47.3 & 22.4 & 0.0 & 0.0 & 0.0 & 0.5 & 8.8 & 9.3 & 21.1 & 30.4 \\
\hline & $12 \mathrm{FA}$ & 40.0 & 19.7 & 12.9 & 0.0 & 0.0 & 2.1 & 4.5 & 6.6 & 20.7 & 27.3 \\
\hline & $24 \mathrm{FA}$ & 33.1 & 16.2 & 29.5 & 0.0 & 0.0 & 1.2 & 3.4 & 4.6 & 16.6 & 21.2 \\
\hline
\end{tabular}


Table 5 Mass loss values of samples obtained by TG-DTG.

\begin{tabular}{|c|c|c|c|c|c|c|c|c|}
\hline \multirow{3}{*}{$\begin{array}{l}\text { Curing } \\
\text { condition }\end{array}$} & \multirow{3}{*}{ Mix } & \multicolumn{6}{|c|}{ Mass loss (wt.\%) } & \multirow{3}{*}{$\begin{array}{c}\mathrm{CO}_{2} \\
\text { sequestration }\end{array}$} \\
\hline & & \multicolumn{2}{|c|}{ Dehydration } & \multicolumn{2}{|c|}{$\begin{array}{l}\text { Decomposition/ } \\
\text { Dehydroxylation }\end{array}$} & Decarbonation & \multirow{2}{*}{ Total } & \\
\hline & & $\begin{array}{c}\text { C/M-S-H, } \\
\mathrm{Et}^{1}, \& \text { HMCs }\end{array}$ & $\mathrm{Ht}^{2}$ & $\begin{array}{c}\text { Ht \& } \\
\text { Portlandite }\end{array}$ & HMCs & HMCs\&Calcite & & \\
\hline \multirow{3}{*}{ Ambient } & 0FA & 4.7 & 3.2 & 3.4 & - & 2.7 & 13.9 & - \\
\hline & $12 \mathrm{FA}$ & 4.2 & 3.8 & 4.0 & - & 1.8 & 13.8 & - \\
\hline & $24 \mathrm{FA}$ & 3.9 & 3.3 & 3.7 & - & 3.8 & 14.7 & - \\
\hline \multirow{3}{*}{ НTPC } & T.0FA & 3.7 & 2.2 & 3.7 & - & 3.5 & 13.1 & - \\
\hline & T.12FA & 4.0 & 2.9 & 3.2 & - & 3.1 & 13.2 & - \\
\hline & T.24FA & 2.6 & 2.9 & 3.5 & - & 4.0 & 13.0 & - \\
\hline \multirow{3}{*}{$\begin{array}{l}\text { Ambient } \\
\text { and } \\
\text { carbonation }\end{array}$} & 0FA & 5.0 & 2.4 & 3.2 & 3.4 & 7.9 & 21.9 & 33.0 \\
\hline & $12 \mathrm{FA}$ & 4.5 & 1.5 & 3.8 & 4.1 & 7.4 & 21.2 & 35.6 \\
\hline & $24 \mathrm{FA}$ & 4.3 & 1.8 & 3.9 & 3.9 & 6.7 & 20.5 & 18.2 \\
\hline \multirow{3}{*}{$\begin{array}{l}\text { HTPC and } \\
\text { carbonation }\end{array}$} & T.0FA & 4.6 & 1.3 & 3.4 & 2.6 & 6.6 & 18.5 & 19.0 \\
\hline & T.12FA & 4.1 & 1.6 & 3.1 & 2.5 & 5.2 & 16.5 & 12.6 \\
\hline & T.24FA & 3.5 & 1.8 & 2.9 & 2.7 & 4.9 & 15.8 & 5.6 \\
\hline
\end{tabular}

${ }^{1}$ Ettringite

${ }^{2}$ Hydrotalcite 


\section{List of Figures}

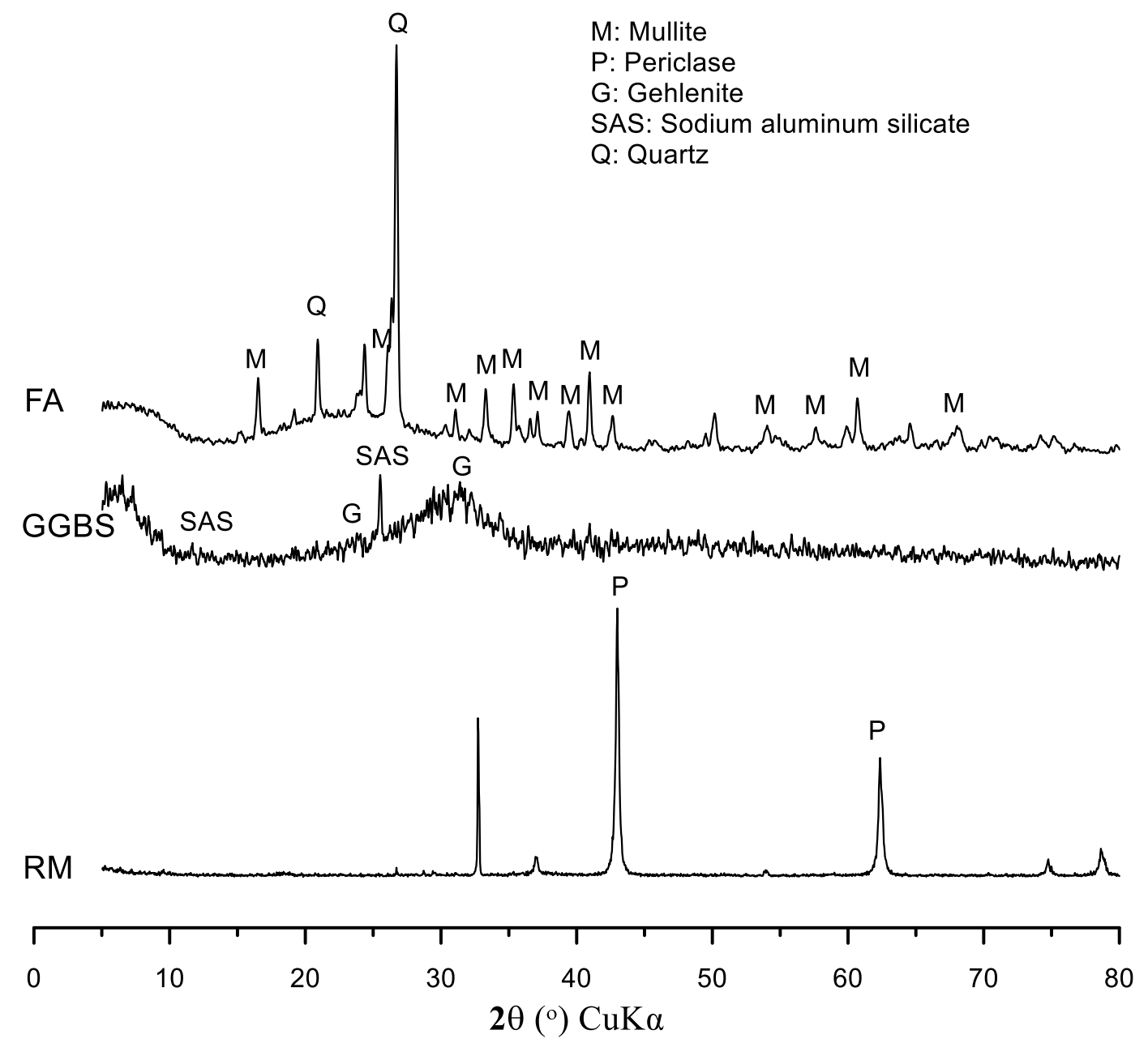

Fig. 1 XRD patterns of RM, GGBS and FA 


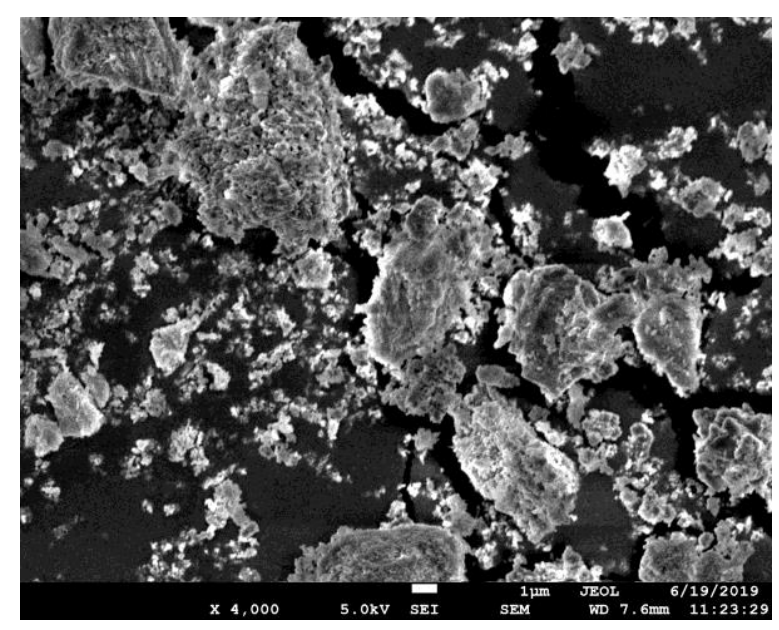

(a)

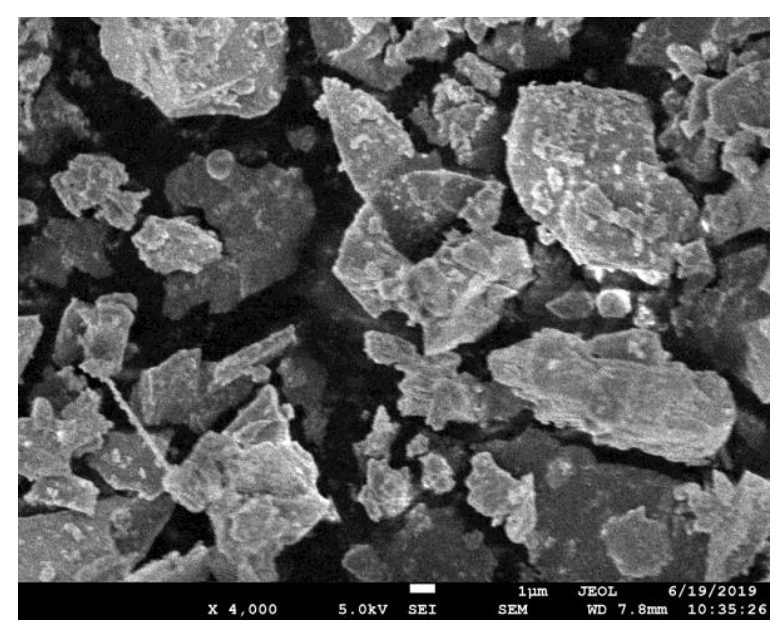

(b)

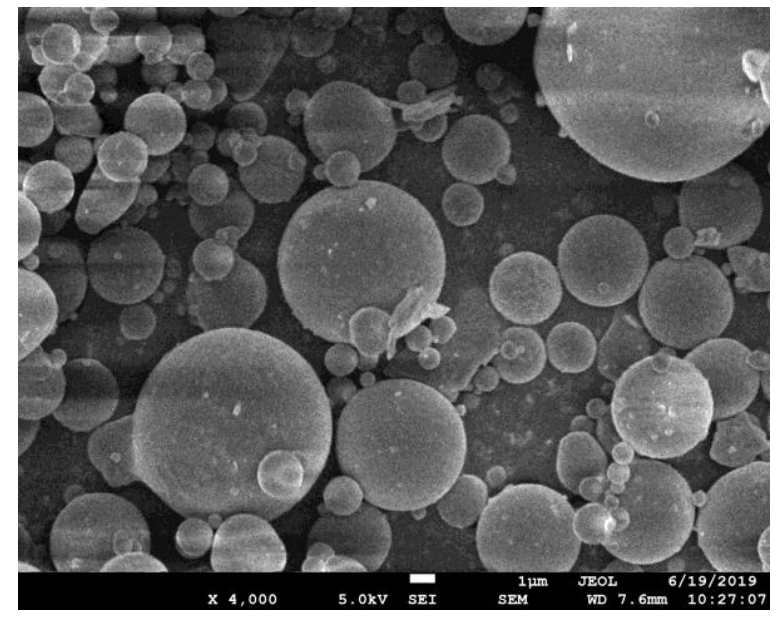

(c)

Fig. 2 SEM images of (a) RM, (b) GGBS and (c) FA 


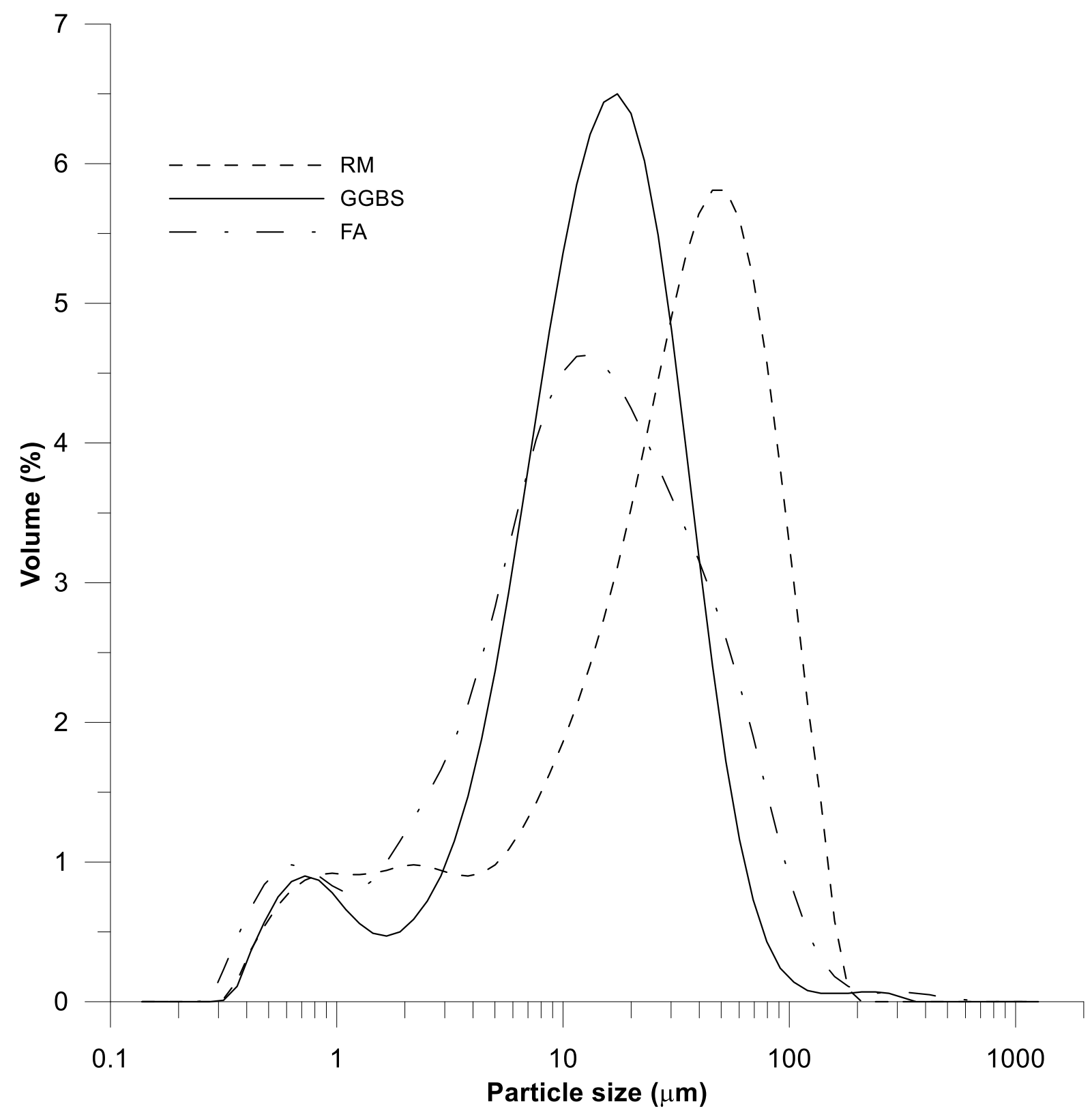

Fig. 3 Particle size distribution of RM, GGBS and FA 

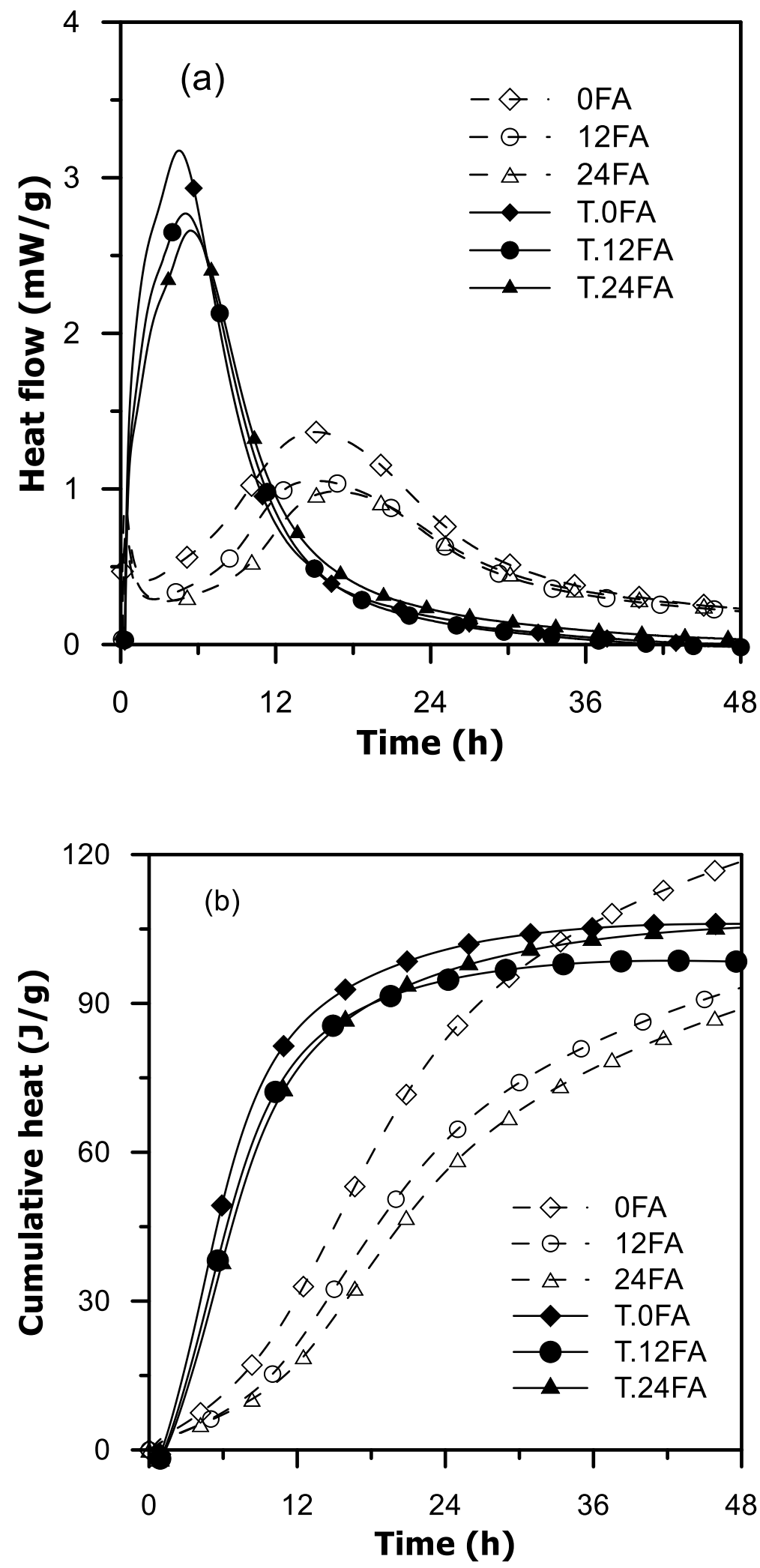

Fig. 4 Isothermal calorimetry data of pastes, showing: (a) heat flow and (b) cumulative heat 

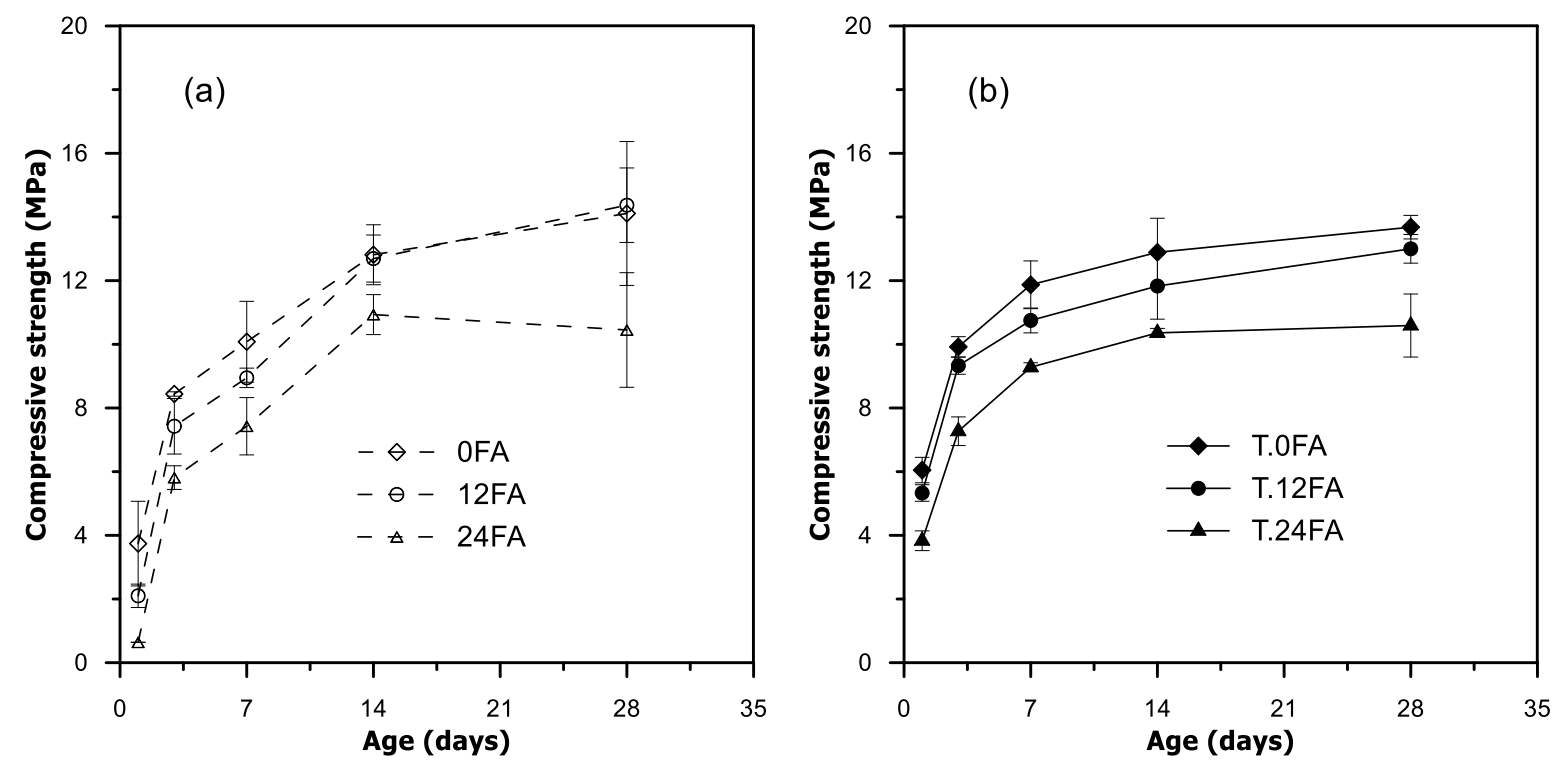

Fig. 5 Compressive strengths of samples cured under: (a) ambient and (b) HTPC conditions 

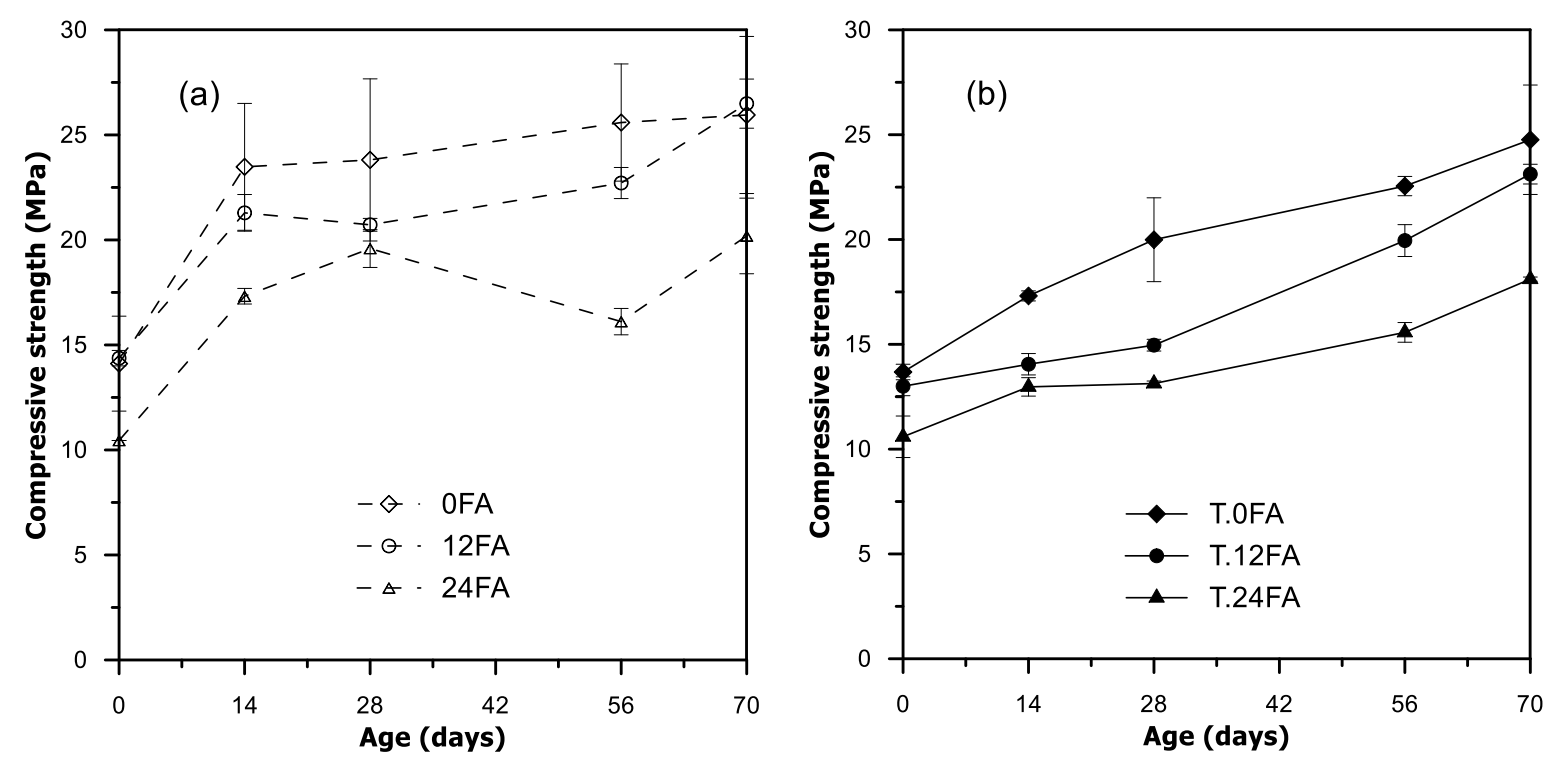

Fig. 6 Compressive strengths of carbonated samples cured under: (a) ambient and (b) HTPC conditions 
B: Brucite

CA: Calcium aluminum silicate hydrate

(a)

M: Mullite

MA: Magnesium aluminum hydroxide hydrate

$\mathrm{MSH}$ : Magnesium silicate hydrate

Et: Ettringite

$\mathrm{Ht}$ : Hydrotalcite

K: Katoite

P: Periclase

PI: Portlandite

F: Calcium fluoride

Q: Quartz
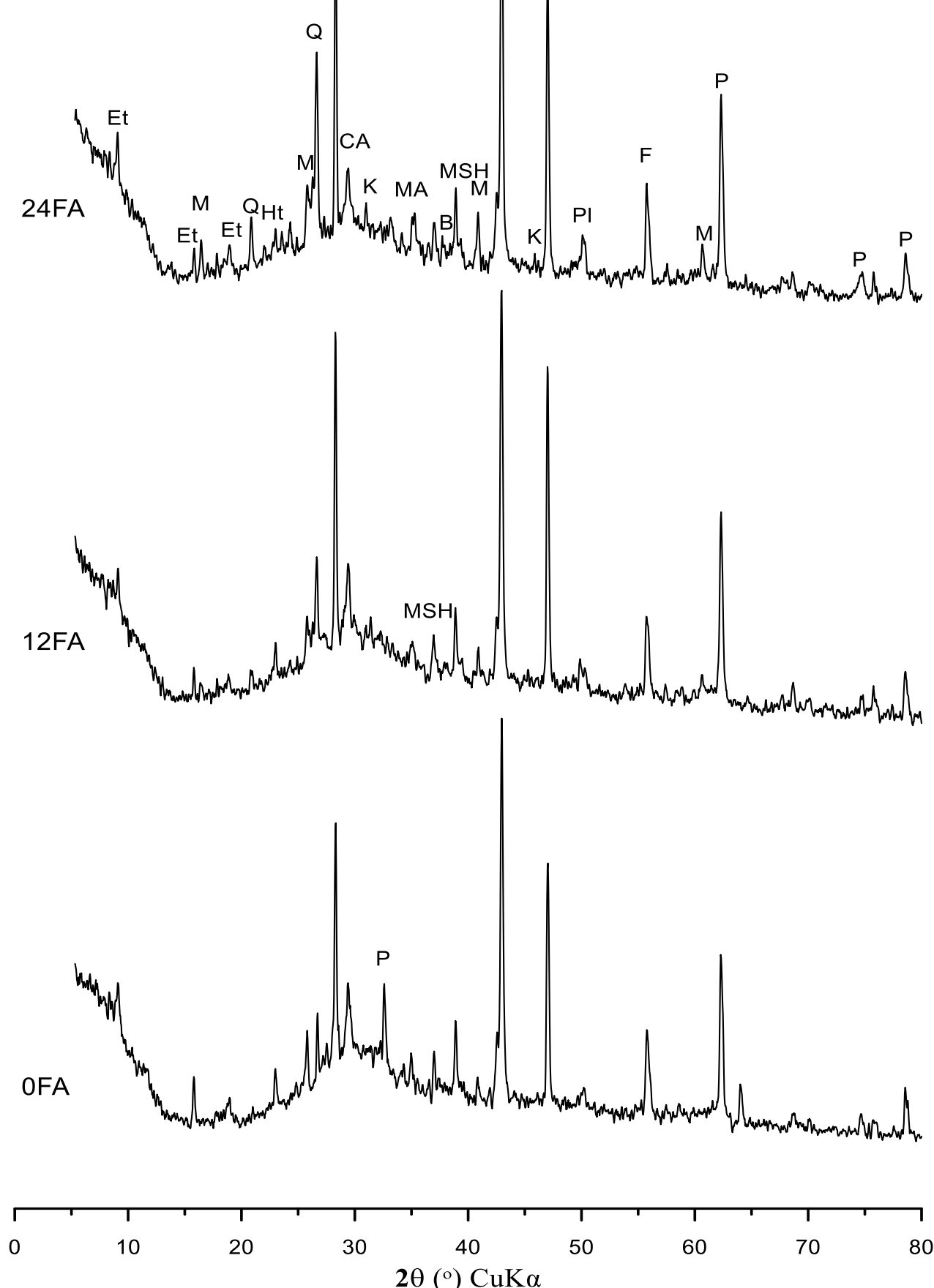
B: Brucite

CA: Calcium aluminum silicate hydrate

M: Mullite

MA: Magnesium aluminum hydroxide hydrate

MSH: Magnesium silicate hydrate

Et: Ettringite

$\mathrm{Ht}$ : Hydrotalcite

K: Katoite

$\mathrm{P}$ : Periclase

PI: Portlandite

F: Calcium fluoride

Q: Quartz
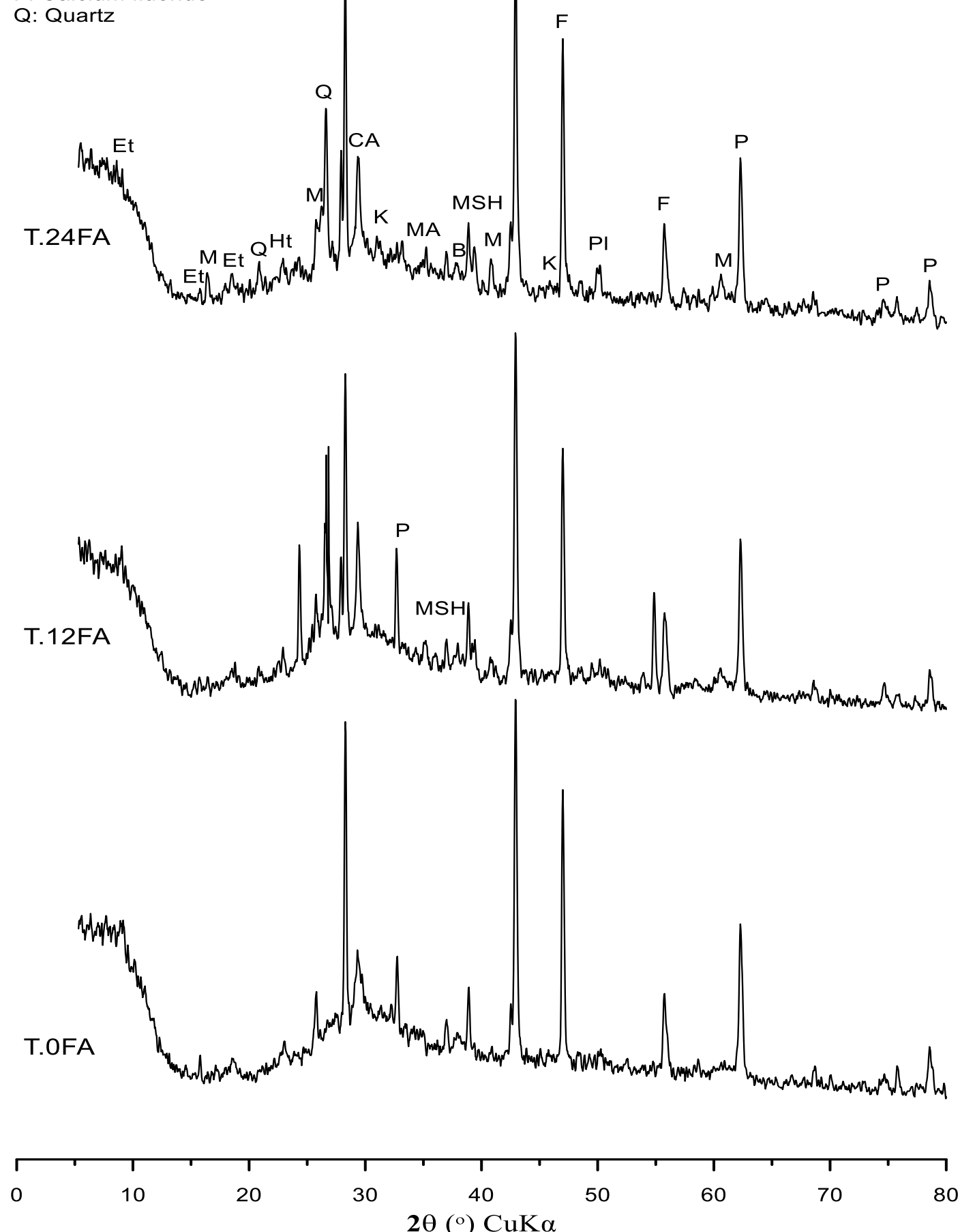

$2 \theta\left(^{\circ}\right) \mathrm{CuK} \alpha$

Fig. 7 XRD patterns of samples after 28 days of curing under: (a) ambient and (b) HTPC conditions 
A: Artinite
B: Brucite
C: Calcite

CA: Calcium aluminum silicate hydrate

M: Mullite

MA: Magnesium aluminum hydroxide hydrate

$\mathrm{MSH}$ : Magnesium silicate hydrate

Et: Ettringite

(a)

$\mathrm{H}$ :Hydromagnesite

Ht: Hydrotalcite

$P$ : Periclase

PI: Portlandite

F: Calcium fluoride

Q: Quartz

24FA

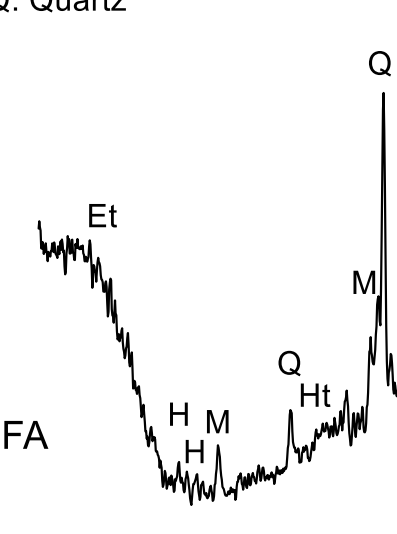

F

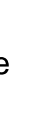
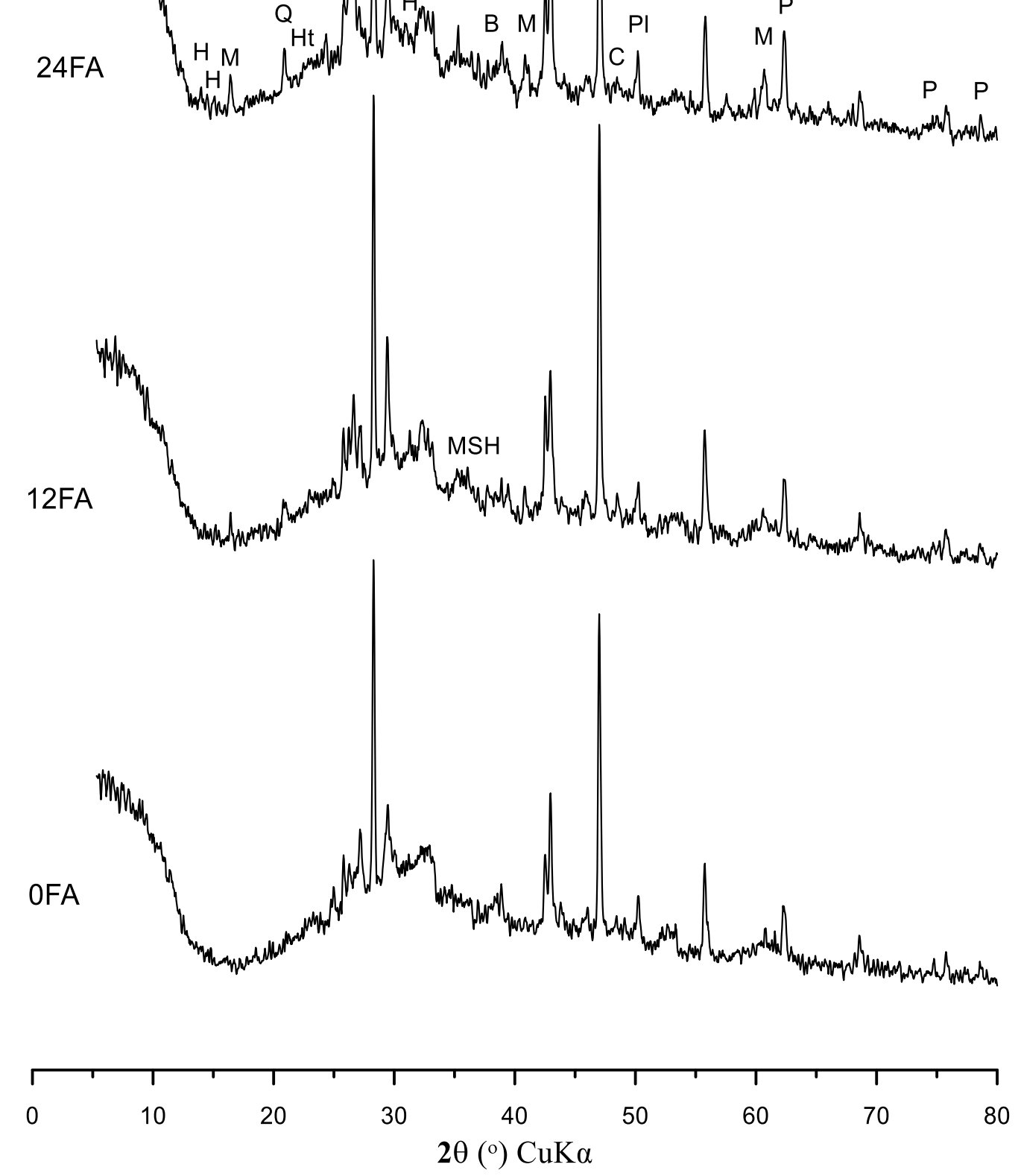


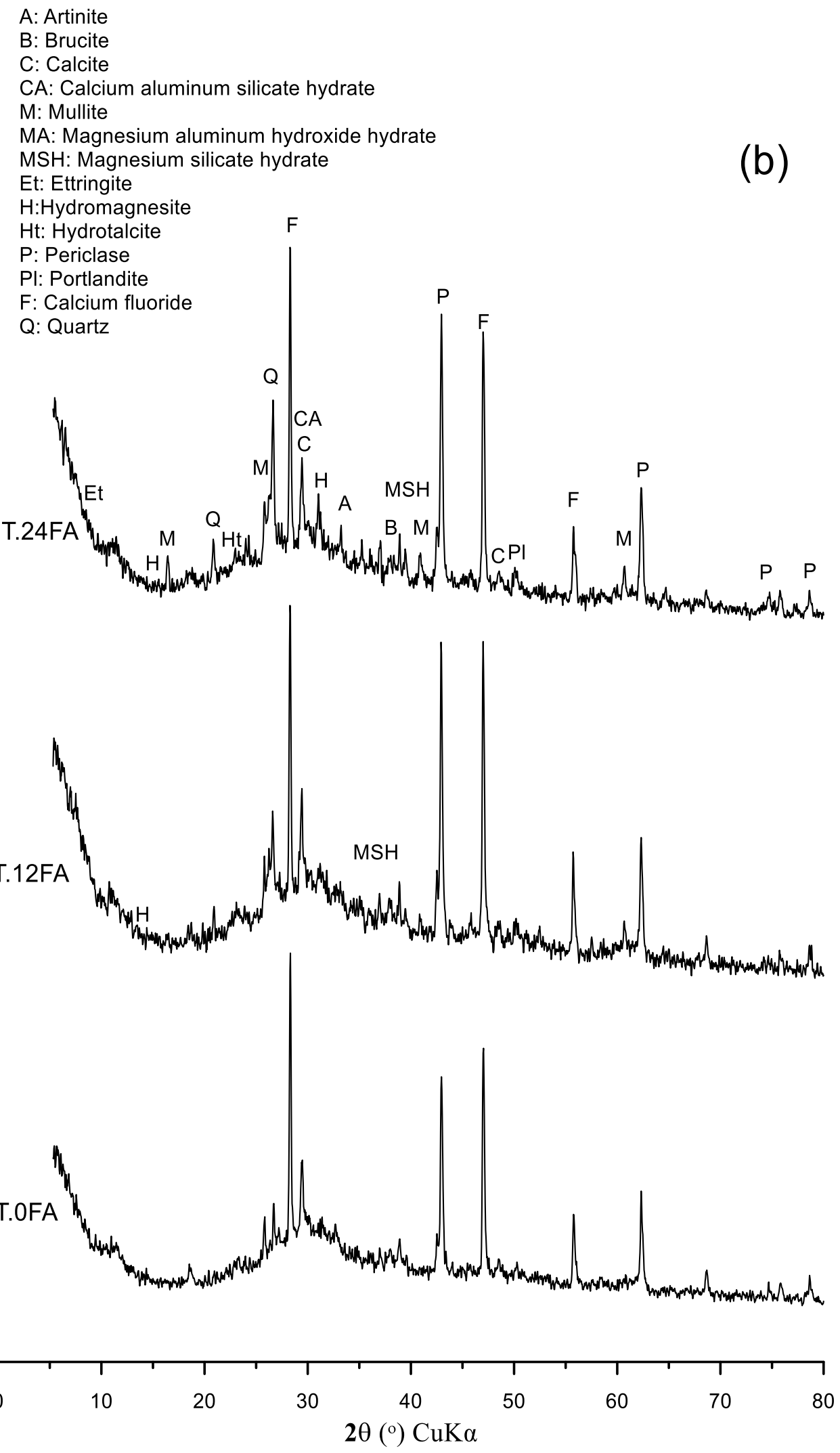

Fig. 8 XRD patterns of samples after: (a) 28 days of ambient curing followed by 56 days of carbonation and (b) 28 days of HTPC followed by 56 days of carbonation 

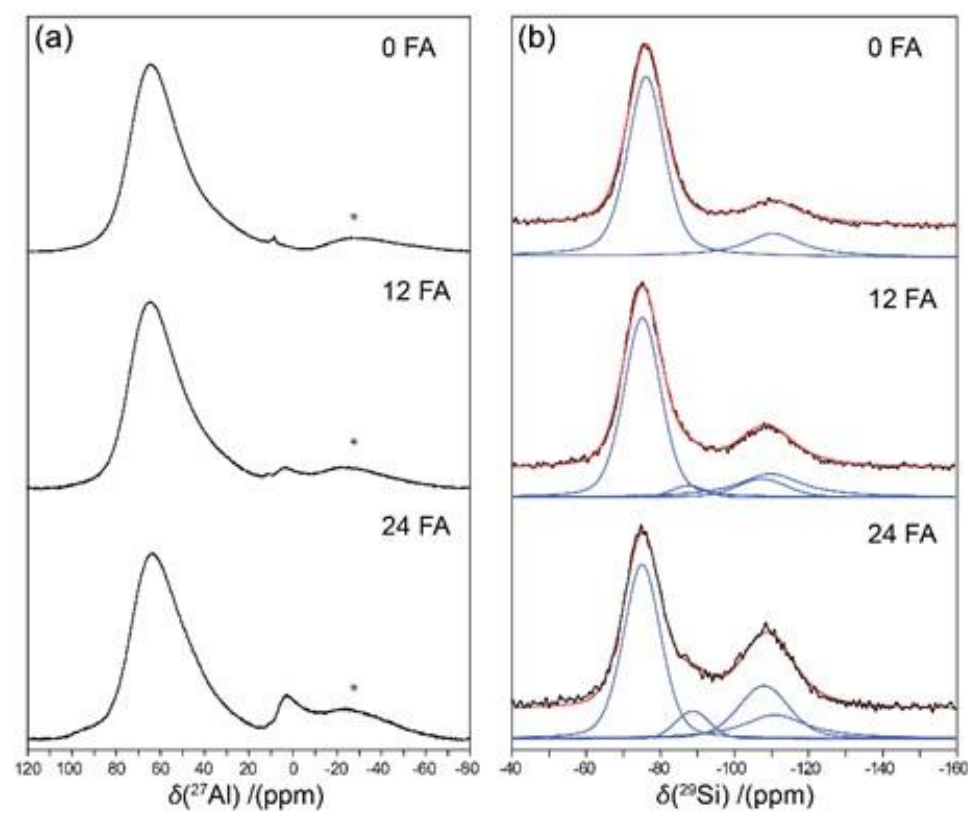

Fig. 9 The (a) ${ }^{27} \mathrm{Al}$ and (b) ${ }^{29} \mathrm{Si}$ MAS NMR spectra of 0FA, 12FA and 24FA precursor mixes

(Experimental spectra, simulated line shapes and deconvoluted simulation components are given by black, red and blue lines, repsectively. Spinning sidebands are marked by asterixes $(*))$ 

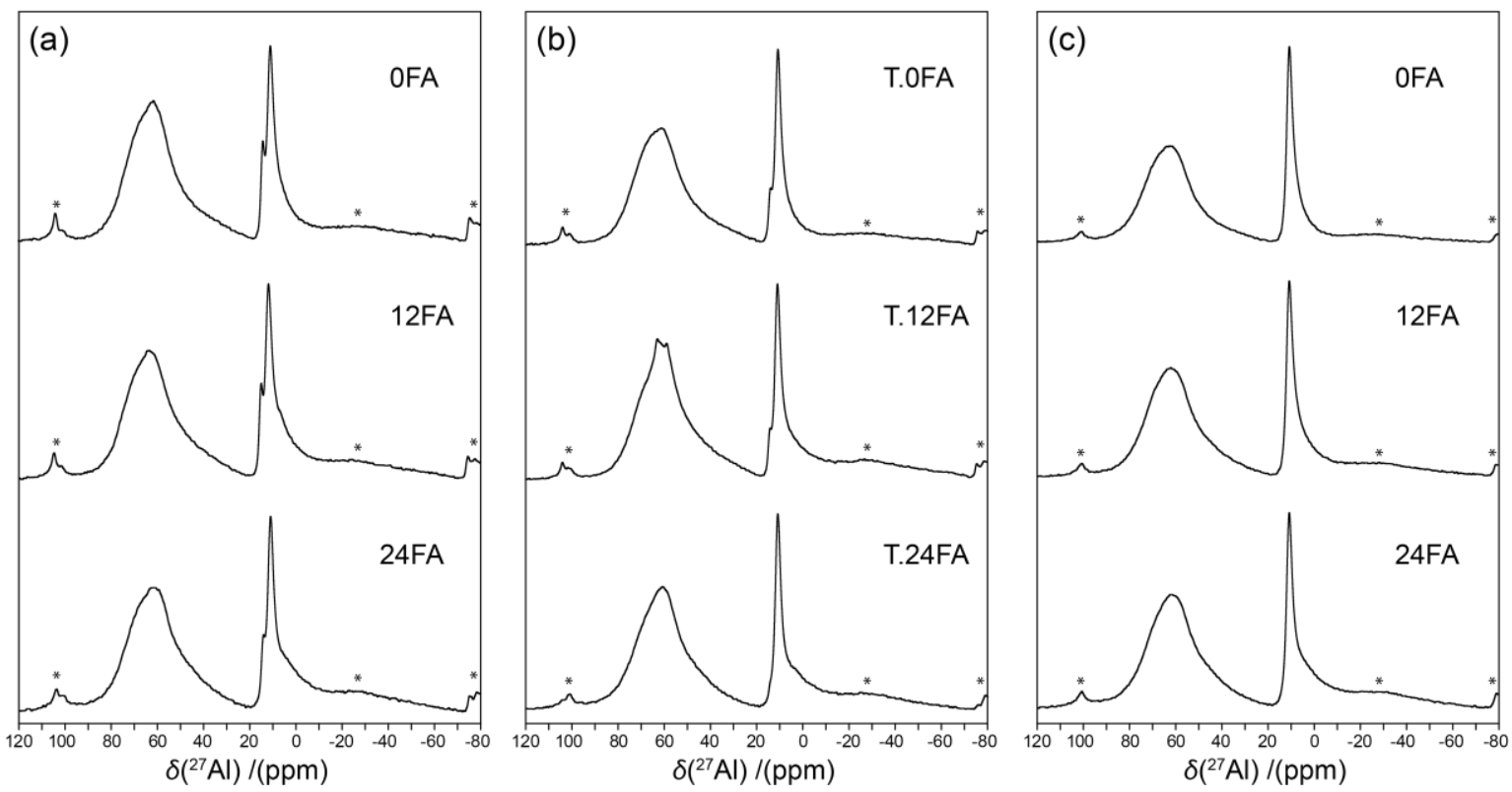

Fig. 10 The ${ }^{27} \mathrm{Al}$ MAS NMR spectra of samples after 28 days of curing under: (a) ambient and (b) HTPC conditions; and (c) 28 days of ambient curing followed by 56 days of carbonation

(Spinning sidebands are marked by asterixes $(*)$ ) 

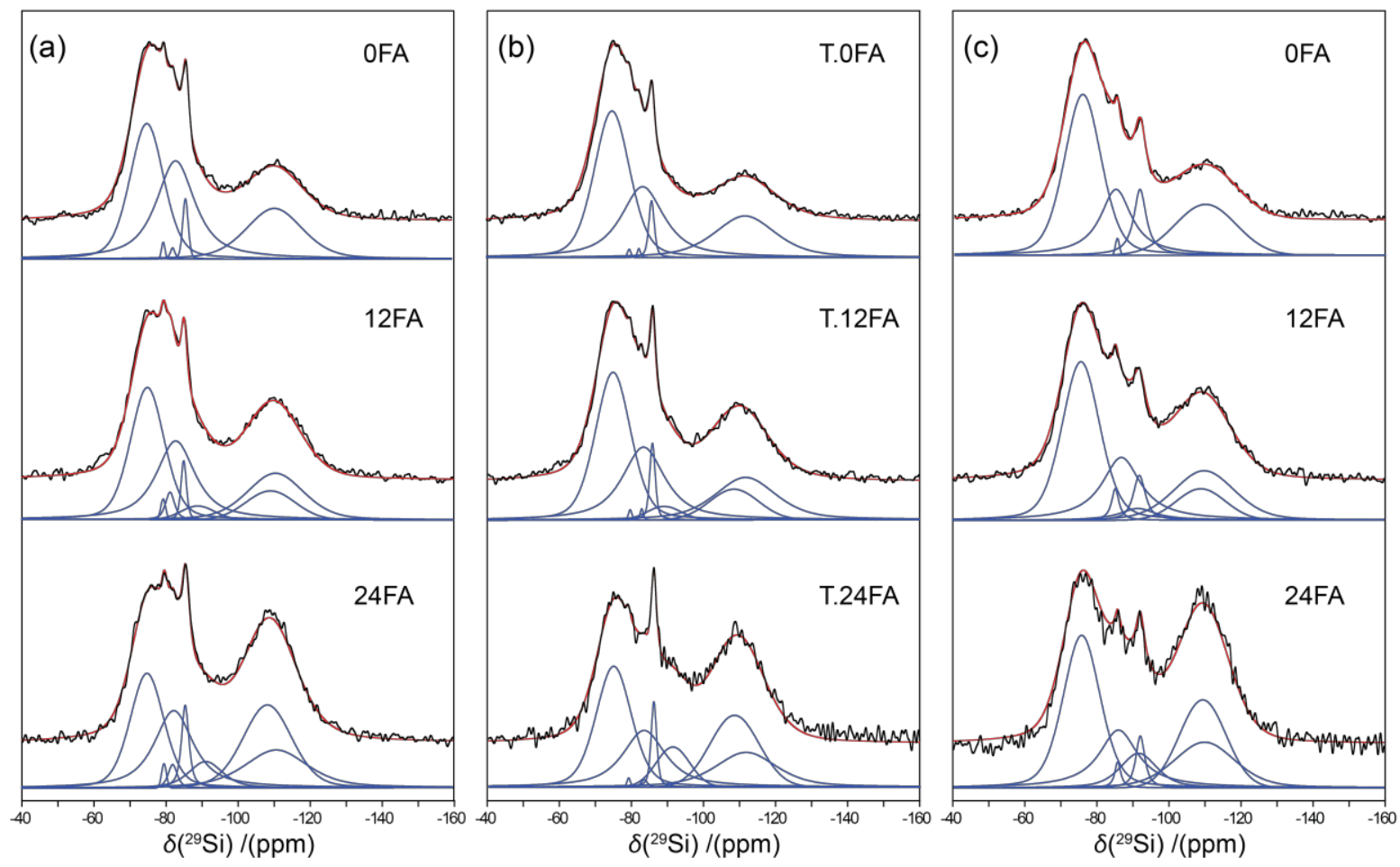

Fig. 11 The ${ }^{29}$ Si MAS NMR spectra of samples after 28 days of curing under: (a) ambient and (b) HTPC conditions; and (c) 28 days of ambient curing followed by 56 days of carbonation

(Experimental spectra, simulated line shapes and deconvoluted simulation components are given by black, red and blue lines, repsectively. Spinning sidebands are marked by asterixes 

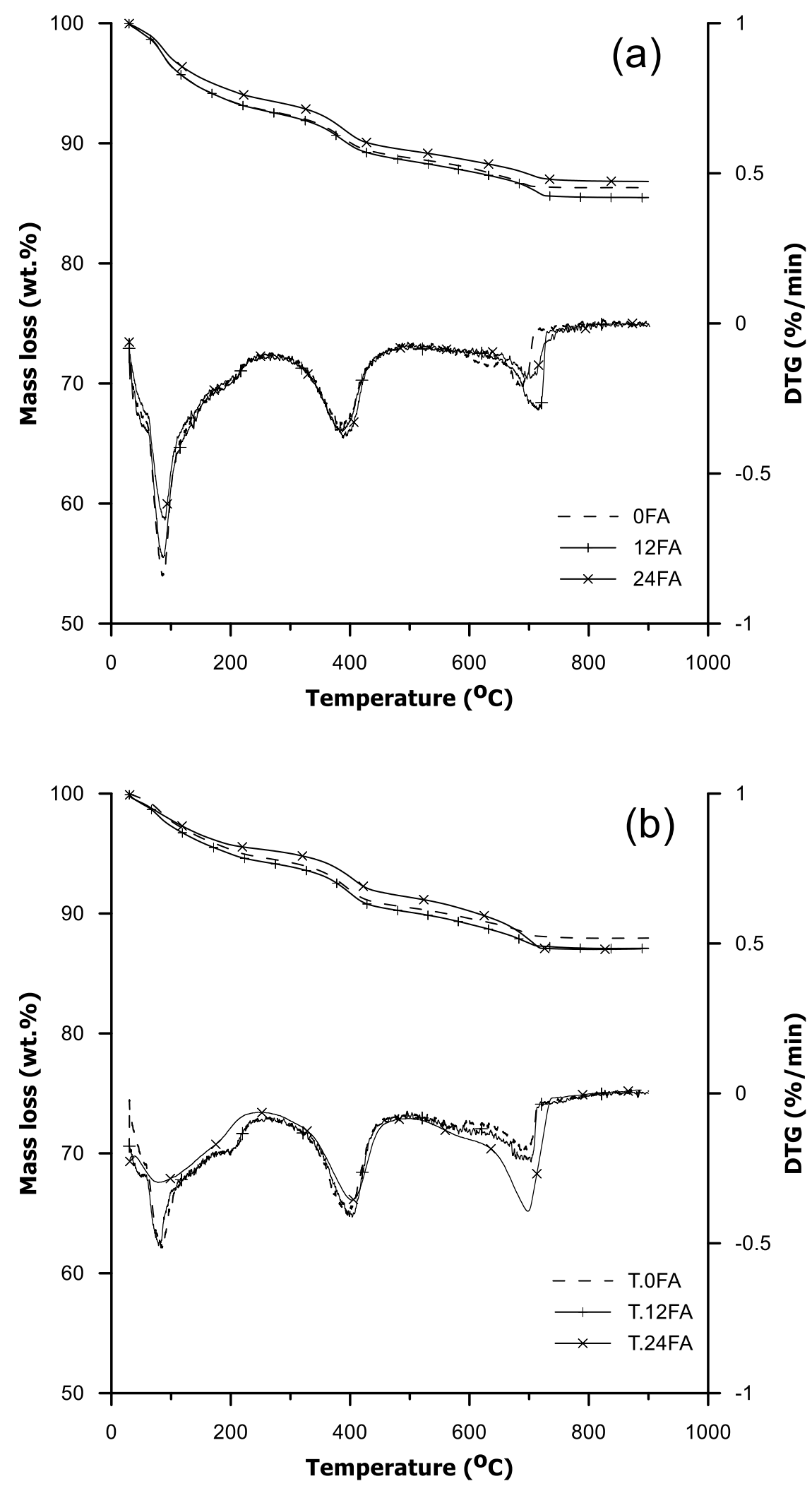

Fig. 12 TG and DTG curves of samples after 28 days of curing under: (a) ambient and (b) HTPC conditions 

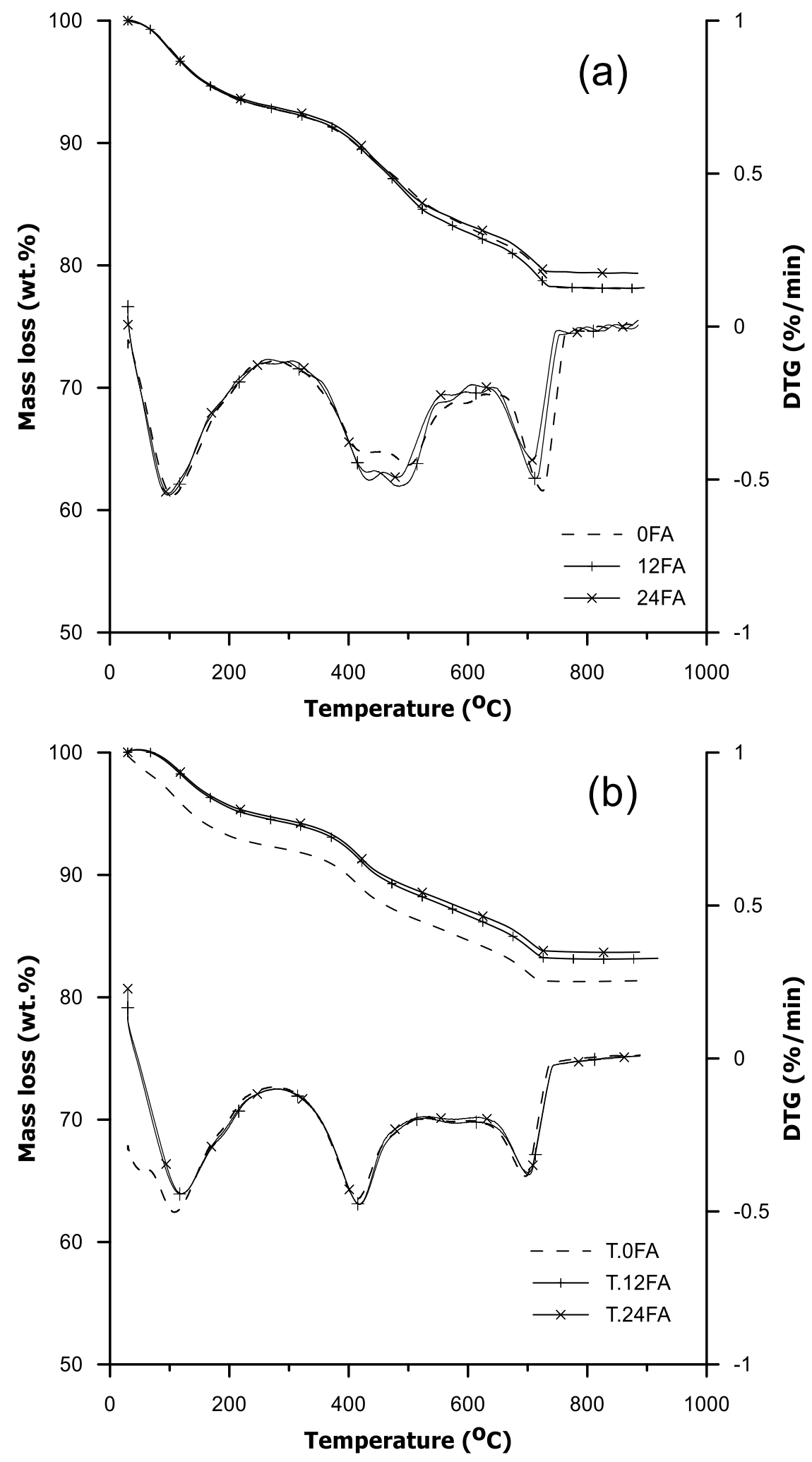

Fig. 13 TG and DTG curves of ambient samples after 28 days of ambient curing followed by 56 days of carbonation 


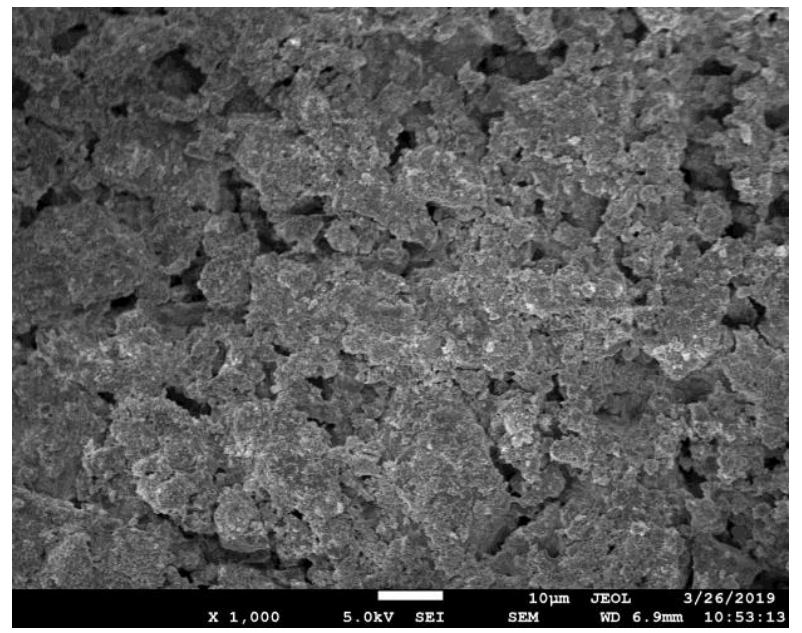

(a)

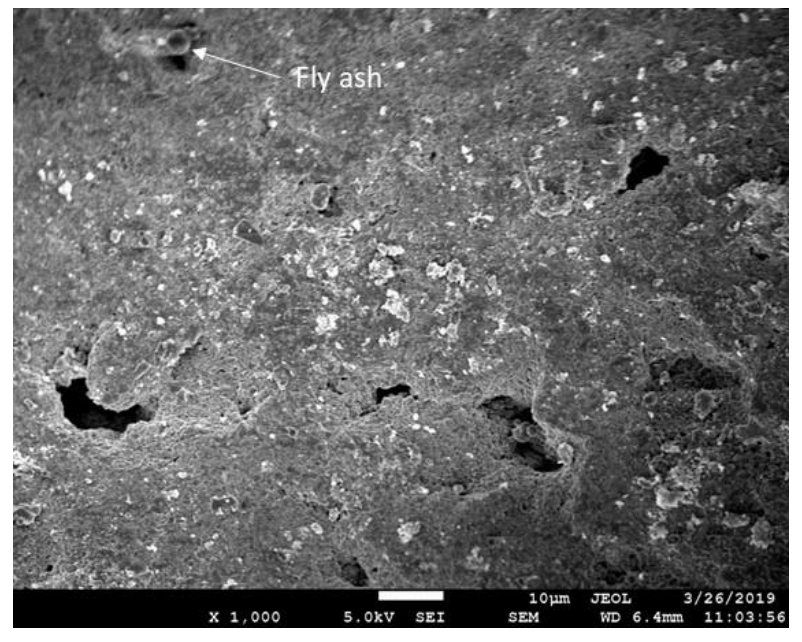

(b)

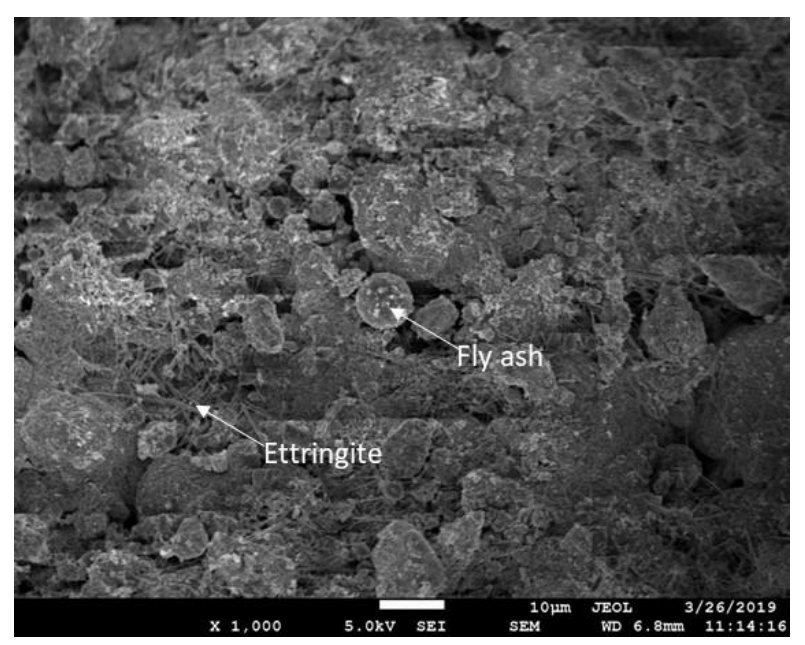

(c)

Fig. 14 SEM images of samples after 28 days of ambient curing: (a) 0FA, (b) 12FA and (c) 24FA 


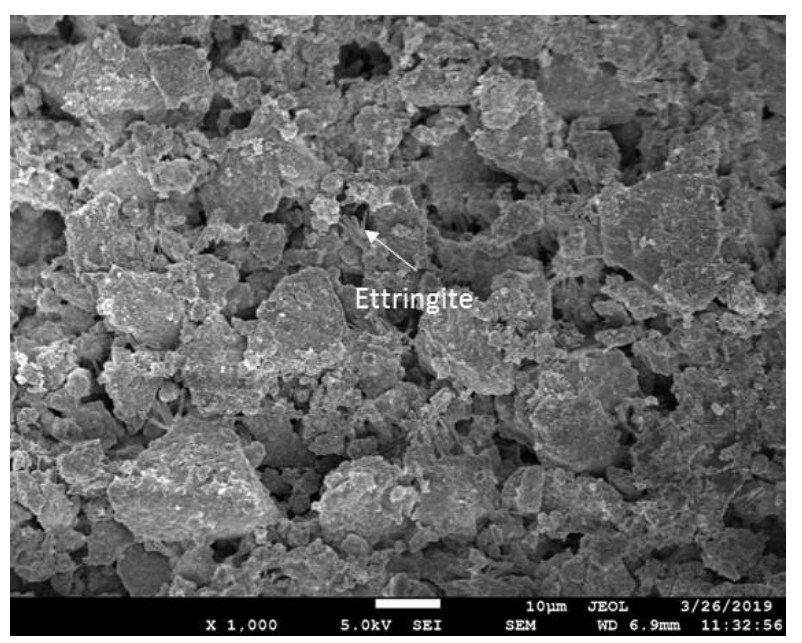

(a)

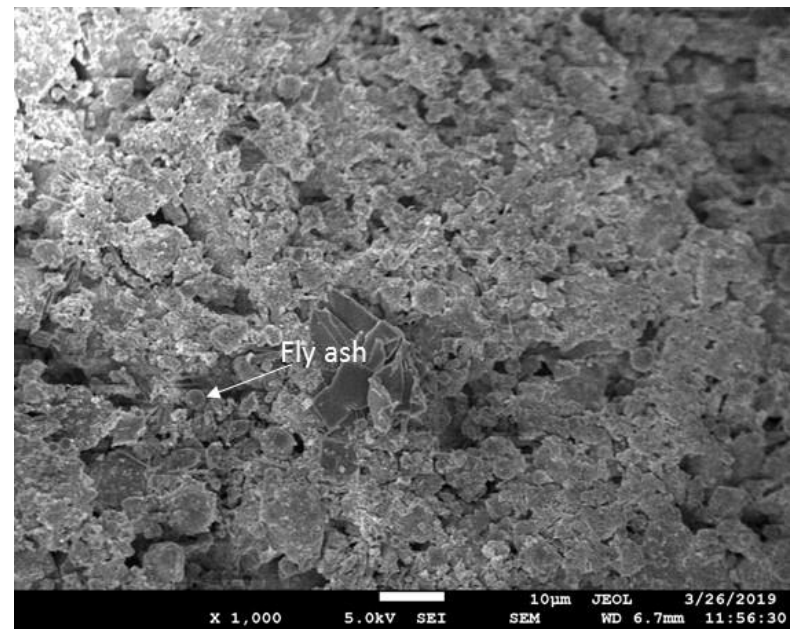

(b)

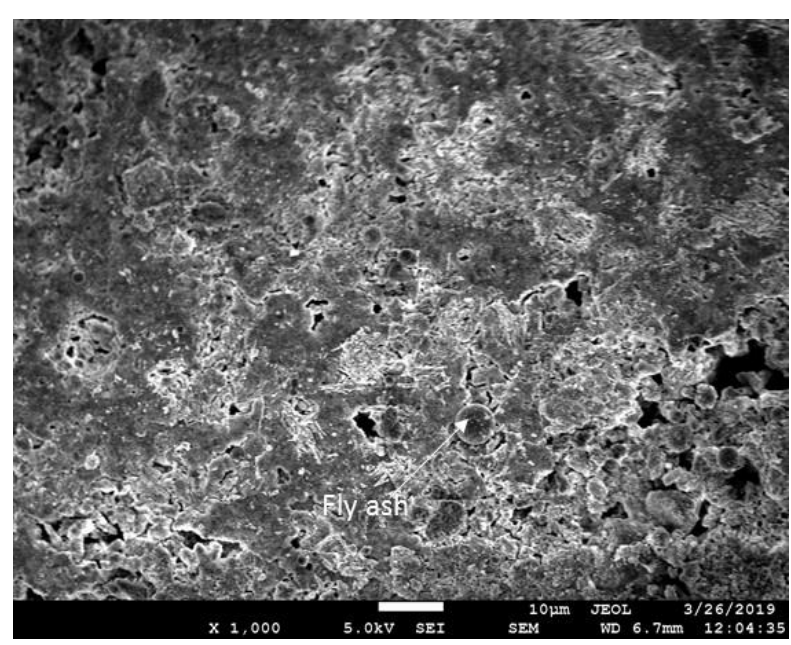

(c)

Fig. 15 SEM images of samples after 28 days of HTPC: (a) T.0FA, (b) T.12FA and (c) T.24FA 


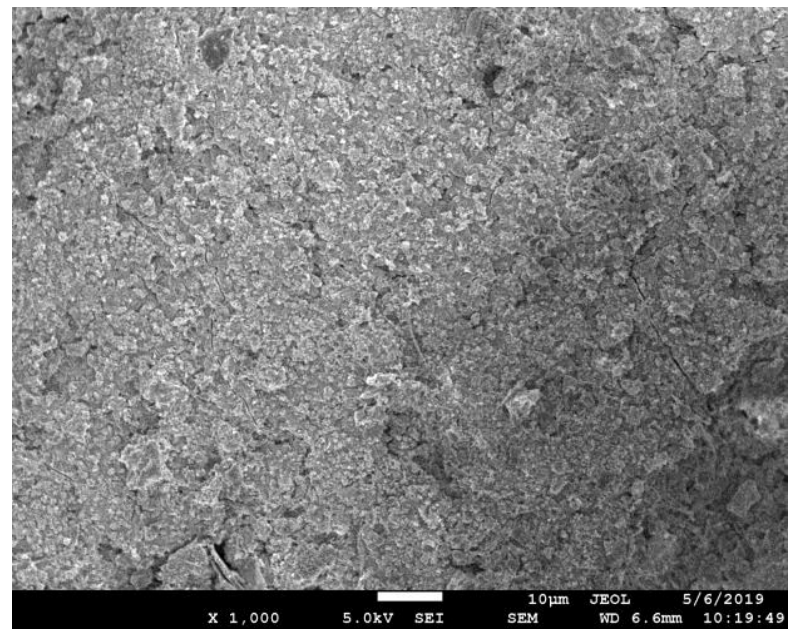

(a)

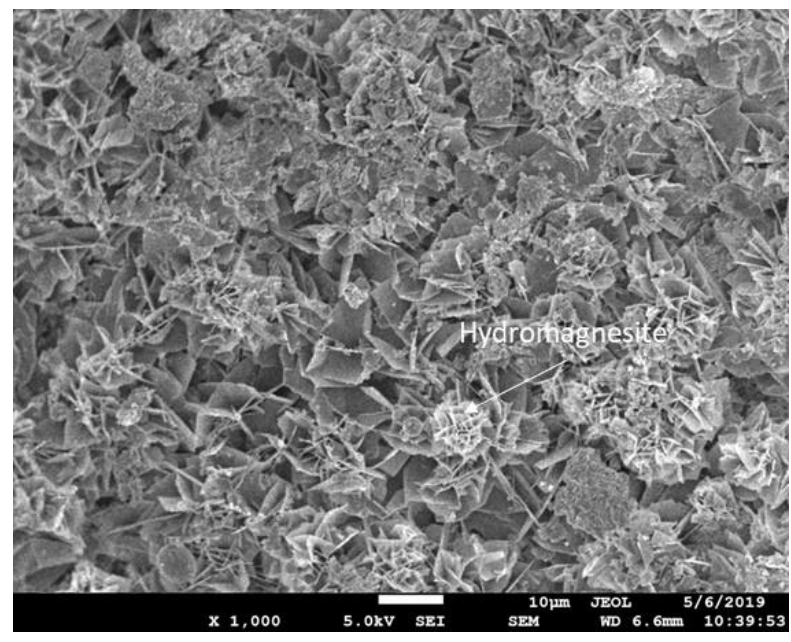

(b)

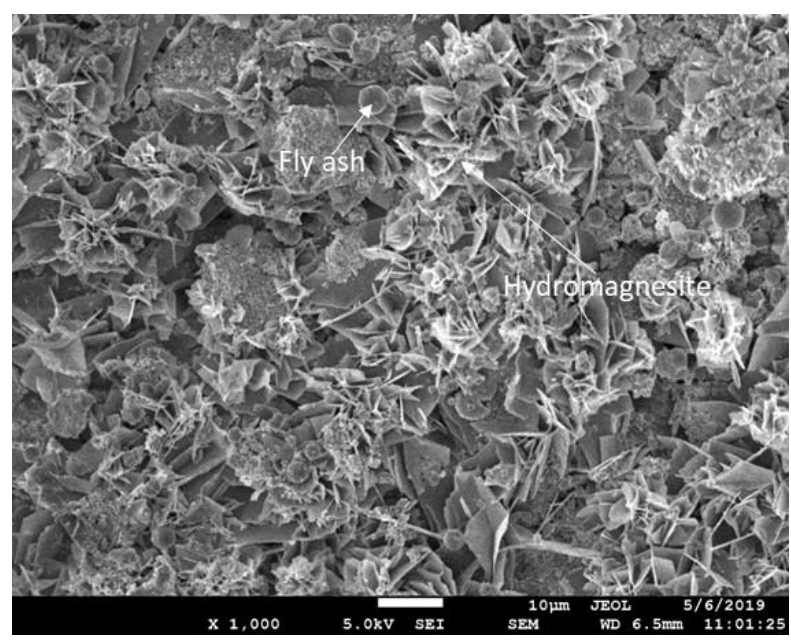

(c)

Fig. 16 SEM images of samples after 28 days of ambient curing followed by 56 days of carbonation: (a) 0FA, (b) 12FA and (c) 24FA 


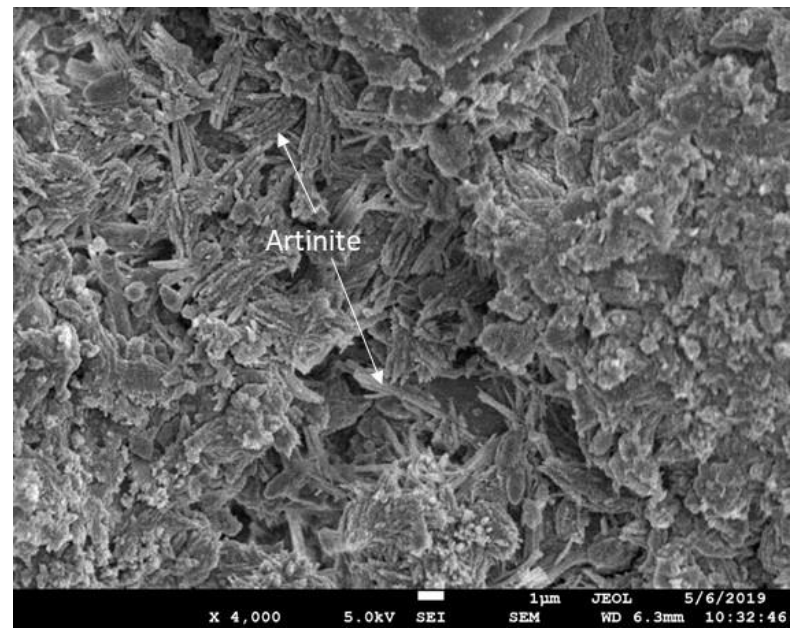

(a)

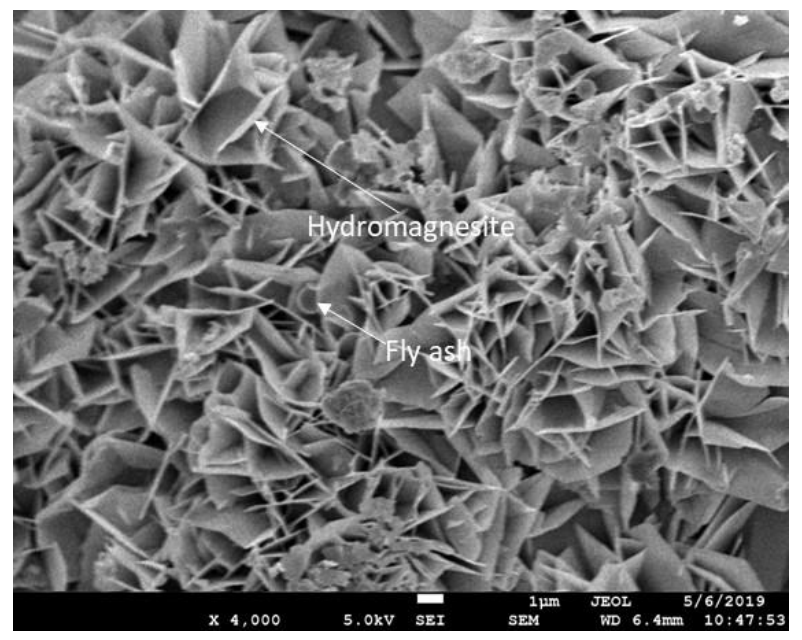

(b)

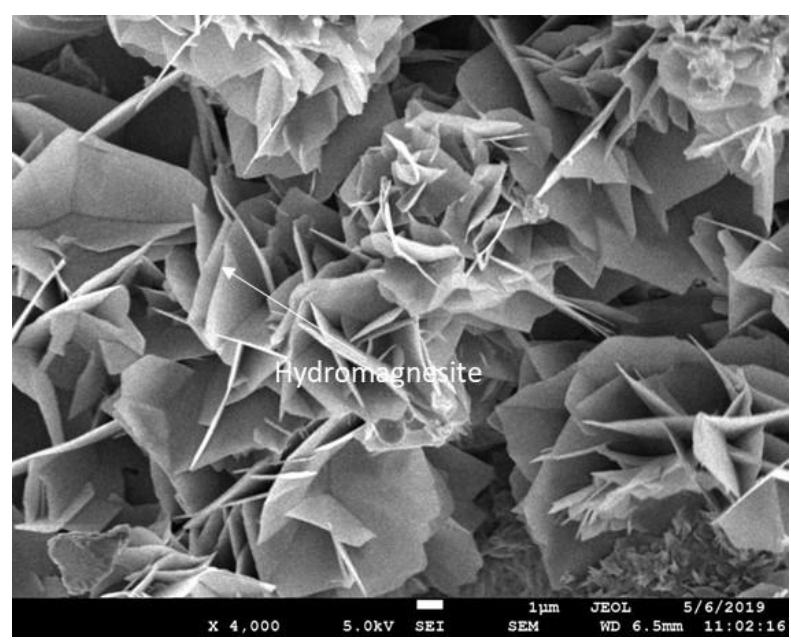

(c)

Fig. 17 Detailed microstructures of samples after 28 days of ambient curing followed by 56 days of carbonation: (a) 0FA, (b) 12FA and (c) 24FA 


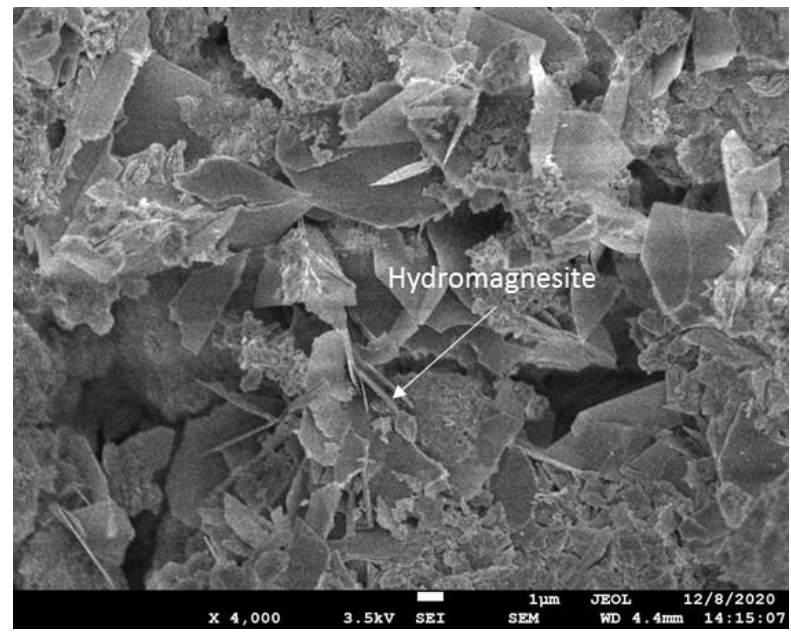

(a)

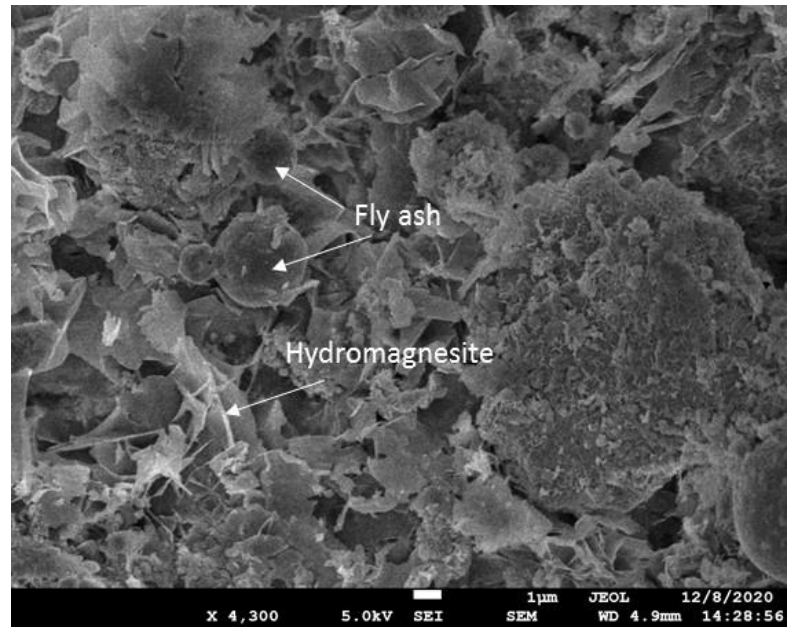

(b)

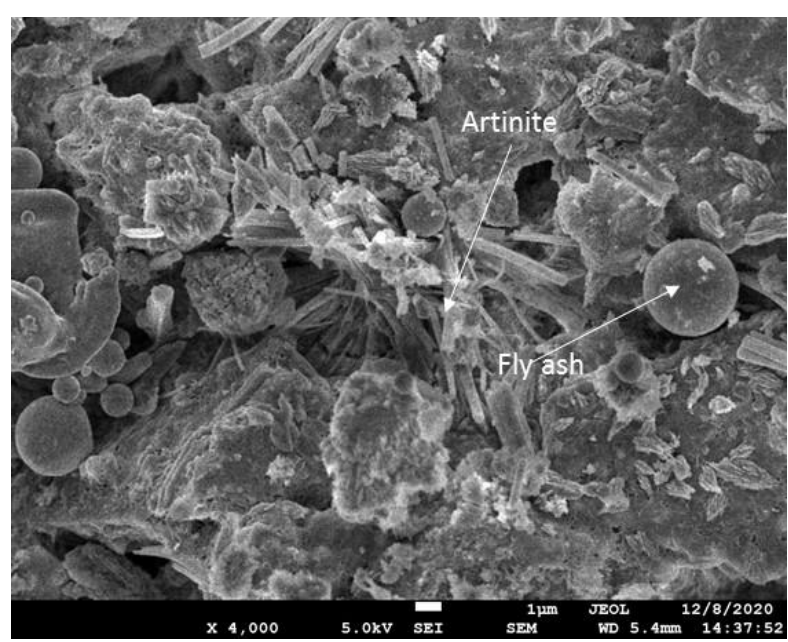

(c)

Fig. 18 Detailed microstructures of samples after 28 days of HTPC followed by 56 days of carbonation: (a) T.0FA, (b) T.12FA and (c) T.24FA 